NBER WORKING PAPER SERIES

\title{
THE ROLE OF BEHAVIORAL FRICTIONS IN \\ HEALTH INSURANCE MARKETPLACE ENROLLMENT AND RISK: \\ EVIDENCE FROM A FIELD EXPERIMENT
}

\author{
Richard Domurat \\ Isaac Menashe \\ Wesley Yin
}

Working Paper 26153

http://www.nber.org/papers/w26153

\author{
NATIONAL BUREAU OF ECONOMIC RESEARCH \\ 1050 Massachusetts Avenue \\ Cambridge, MA 02138 \\ August 2019
}

We thank John Bertko, Tom Chang, Amy Finkelstein, Craig Fox, Ori Heffetz, Ted O'Donoghue, Sarah Reber, Jessie Shapiro, Josh Tasoff, Robert Town and seminar participants at Claremont Graduate University, Covered California, the University of Maryland, University of Chicago, the Wharton School at the University of Pennsylvania, and the J-PAL North America Health Care Delivery Conference for comments. We also thank Leah Horgan for graphic design, Sam Lau for research assistance, and Carolina Arteaga, Niza Muñoz, Bianca Vargas and Maria Lucia Yanguas for their translations. We thank Jim Watkins at the State of California's Department of Health Care Services. Finally, we are grateful to our collaborators at Covered California. We are especially thankful to Ahmed Al-Dulaimi, James DeBenedetti, Andrew Feher, Raymond Jacobs, Lance Lang, Peter Lee, Allie Mangiaracino, Vishaal Pegany, Katie Ravel, and Colleen Stevens. This study was supported by the Abdul Latif Jameel Poverty Action Lab, North America. All errors are our own. The views expressed herein are those of the authors and do not necessarily reflect the views of the National Bureau of Economic Research.

At least one co-author has disclosed a financial relationship of potential relevance for this research. Further information is available online at http://www.nber.org/papers/w26153.ack

NBER working papers are circulated for discussion and comment purposes. They have not been peer-reviewed or been subject to the review by the NBER Board of Directors that accompanies official NBER publications.

(C) 2019 by Richard Domurat, Isaac Menashe, and Wesley Yin. All rights reserved. Short sections of text, not to exceed two paragraphs, may be quoted without explicit permission provided that full credit, including $\odot$ notice, is given to the source. 
The Role of Behavioral Frictions in Health Insurance Marketplace Enrollment and Risk: Evidence from a Field Experiment

Richard Domurat, Isaac Menashe, and Wesley Yin

NBER Working Paper No. 26153

August 2019

JEL No. D03,I11,I13

\begin{abstract}
$\underline{\text { ABSTRACT }}$
We experimentally varied information mailed to 87,000 households in California's health insurance marketplace to study the role of frictions in insurance take-up. Reminders about the enrollment deadline raised enrollment by $1.3 \mathrm{pp}$ (16 percent), in this typically low take-up population. Heterogeneous effects of personalized subsidy information indicate systematic misperceptions about program benefits. Consistent with an adverse selection model with frictional enrollment costs, the intervention lowered average spending risk by 5.1 percent, implying that marginal respondents were 37 percent less costly than inframarginal consumers. We observe the largest positive selection among low income consumers, who exhibit the largest frictions in enrollment. Finally, the intervention raised average consumer WTP for insurance by $\$ 25$ to $\$ 54$ per month. These results suggest that frictions may partially explain low measured WTP for marketplace insurance, and that interventions reducing them can improve enrollment and market risk in exchanges.

Richard Domurat

University of California at Los Angeles

3250 Public Affairs Building

Los Angeles, CA 90095

Richard.domurat@ucla.edu

Isaac Menashe

Covered California

1601 Exposition Boulevard

Sacramento, CA 95815

Isaac.Menashe@covered.ca.gov

Wesley Yin

University of California, Los Angeles

3250 Public Affairs Building

Los Angeles, CA 90095

and NBER

wyin@ucla.edu
\end{abstract}

A data appendix is available at

http://www.nber.org/data-appendix/w26153

A randomized controlled trials registry entry is available at https://www.socialscienceregistry.org/trials/2115 


\section{Introduction}

At any one time, between 10 and 11 million people have health coverage through an exchange created by the Patient Protection and Affordable Care Act (ACA) (CMS 2018), and approximately 30 million people have obtained ACA exchange coverage at some point since their creation in $2014 .{ }^{1}$ As a fraction of eligible enrollees, however, take-up is surprisingly low. Approximately 60 percent of individuals who are eligible for a federal premium subsidy-and 40 percent of lower income individuals eligible for progressive premium and cost-sharing subsidies-forgo the subsidy and remain uninsured. ${ }^{2}$

This is surprising given the availability of federal means-tested premium subsidies, which dramatically reduces premiums to obtain benchmark coverage among low-income consumers. For individuals below 250 percent of the federal poverty level (FPL), the interquartile range for net-of-subsidy premiums of a Bronze plan in California in 2019 was $\$ 1$ to $\$ 10$ per member per month, reflecting an average subsidy of $\$ 371$ per month. ${ }^{3}$ That so many subsidy-eligible people fail to take-up marketplace insurance is consistent with an extensive literature documenting incomplete participation in benefits programs available to economically disadvantaged individuals (Currie 2006).

One explanation is that consumers do not sufficiently value marketplace coverage. In the individual marketplace in Massachusetts, Finkelstein, Hendren and Shepard (2017) find that the take-up rates and price elasticities imply a willingness-to-pay (WTP) of marginal enrollees for coverage that is far below consumers' marginal health care costs. Finkelstein, Hendren and Shepard (2017) explore a number of potential explanations, ultimately pointing to the availability of uncompensated care as a primary factor for why consumers' marginal health care costs exceeds their measured WTP.

Evidence from a growing literature on plan choice suggest another potential explanation for the surprisingly low measured WTP: informational and behavioral frictions. Consumers' lack of awareness of plan attributes, choice complexity, choice overload and inertia can impact both shopping behavior among current enrollees (Ericson et al, 2017) and plan choice (Abaluck and Gruber, 2011; Ketcham et al., 2012; Kling et al. 2012, Handel, 2013, Handel and Kolstad, 2015). Such frictions can result in higher

\footnotetext{
${ }^{1}$ Covered California, which represents approximately one-ninth of the US exchange population, currently covers 1.3 million enrollees, and has covered over 4 million unique individuals since 2014.

${ }^{2}$ See https://www.kff.org/health-reform/state-indicator/marketplace-enrollment-as-a-share-of-the-potentialmarketplace-population-2015/ or https://www.kff.org/uninsured/issue-brief/estimates-of-eligibility-for-acacoverage-among-the-uninsured-in-2016-october-2017-update/.

${ }^{3}$ The most affordable "enhanced" Silver plan (in which cost-sharing is substantially subsidized) would typically cost these consumers $\$ 30$ to $\$ 128$ per month, reflecting an average subsidy of nearly $\$ 455$ per month, including the cost-sharing benefit.
} 
equilibrium pricing (Ericson, 2014) and adverse selection welfare loss (Handel, 2013; Polyakova, 2016; Handel, Kolstad and Spinnewijn, 2018). ${ }^{4}$

These studies suggest that informational and psychological frictions may also impact take-up decisions. Finkelstein, Hendren and Shepard (2017) also raise the possibility that behavioral frictions contribute to the low measured WTP for exchange coverage. But with no existing research on the role of frictions in insurance take-up, they are unable to quantify its importance. ${ }^{5}$ If found, the presence of economically significant behavioral frictions in enrollment decisions would imply different policy responses to encourage coverage take-up than if under-enrollment were due primarily to the presence of uncompensated care.

A distinguishing characteristic of studying frictions in enrollment decisions is the potentially large implication they may have for market risk, with potentially ambiguous effects. If marginal respondents to a new policy are sicker-due to severe lack of information about benefits-average market risk may increase, leading to higher equilibrium premiums and welfare loss. On the other hand, if marginal respondents are healthier-as would be the case if frictions dissuaded healthy consumers from purchasing insurance-average risk may fall, lowering community-rated premiums, and bolstering market stability. The welfare impact of any intervention depends on the correlation between underlying frictions and the health risk of marginal enrollees. The sign of this correlation is particularly important in ACA markets, where adverse selection on the extensive margin may result in more severe welfare loss than selection across plans (Chandra, Gruber and McKnight, 2011, Hackman, Kolstad and Kowalski, 2015; Jaffe and Shepard, 2017; Finkelstein, Hendren and Shepard, 2019), potentially destabilizing markets (Handel, Hendel and Whinston, 2015). Moreover, the impact of any enrollment intervention on

\footnotetext{
${ }^{4}$ In two studies with research designs most similar to this study, Kling et al. (2012) finds that enrolled consumers presented with personalized information in-person about savings from switching plan respond by switching to plans that generate cost-sharing savings over the year, while Ericson et al. (2017) finds that mail and email nudges to shop as, well as personalized information about premium savings, sent to enrolled consumers did not lead to plan switches, but did lead to increased online shopping, indicating the presence of search and hassle costs, and that even low-touch interventions can reduce frictions in part of the plan renewal process.

${ }^{5}$ Evidence from means-tested public programs outside of health care point to behavioral frictions as a potentially important factor in participation decisions. In retirement saving programs and the earned income tax credit (EITC), low program awareness and other informational barriers contribute to low program participation (Smeeding et al., 2000; Chetty and Saez, 2013; Chetty, Friedman and Saez, 2013; Bhargava and Manoli, 2015). Procrastination and inertia deters participation in employer-matched retirement savings (Madrian and Shae, 2001). And psychological frictions such as inattention, complexity, and hassle costs can reduce program participation in anti-poverty programs (Bertrand, Mullainathan and Shafir, 2006) and claiming of EITC benefits (Bhargava and Manoli, 2015).
} 
risk selection into the market can also have important secondary effects on adverse selection within the market, due to equilibrium distribution of risks across plans (Geruso, Leyton and Shepard, 2019).

In this study, we conduct a field experiment to test how reducing informational and behavioral frictions impact enrollment decisions and market risk. We randomly assigned 87,394 California households to receive one of five letter interventions, designed to lower informational and behavioral frictions that could hinder take-up in Covered California, the state's health benefits exchange. We examine how these interventions impact enrollment and the average market risk due to selection of marginal respondents to treatment.

This study makes several contributions, building on recent research on the interaction between behavioral frictions and adverse selection in plan choice (Handel, 2013; Polyakova, 2016; Handel, Kolstad and Spinnewijn, 2018). First, the implications of reducing behavioral frictions in these recent studies are based on counterfactual simulations, where frictions are hypothetically removed in order to assess equilibrium consequences of improved choice. In contrast, this study exploits experimental variation in the reduction of consumer frictions using tools available to policy-makers. Second, we combine our randomized intervention with administrative data on health risk, to test how reductions in frictions impact enrollment and average market risk. To our knowledge, this study is the first to combine a policy-relevant intervention targeting behavioral frictions with health risk data, to identify potential adverse selection implications of frictions in take-up decisions. ${ }^{6}$ Finally, we provide a conceptual framework for how the presence of frictions can impact take-up and measured willingness-to-pay for coverage. We then use our randomized assignment to estimate how reducing behavioral frictions impacts measured willingness-to-pay.

We find that a basic reminder of the enrollment deadline raised enrollment by $1.3 \mathrm{pp}$ (or 16 percent) in this low-uptake population. This evidence is consistent with inattention having an important role in take-up. Among low-income consumers, letters making subsidy and plan comparison information more salient caused enrollment to increase by more than the Basic Reminder letter, implying that low-income consumers may face higher costs of acquiring information or higher hassle cost of purchasing a plan, causing them to underestimate their subsidy benefits. At higher incomes (and correspondingly lower

\footnotetext{
${ }^{6}$ By focusing on frictions in enrollment decision, as opposed to plan choice, we are able to study friction on the extensive margin. The potential for extensive margin adverse selection welfare loss in the ACA markets, which are subject to community rating and guaranteed issue, is thought to dominate welfare losses associated with adverse selection in plan choice (Chandra, Gruber and McKnight, 2011, Hackman, Kolstad and Kowalski, 2015; Jaffe and Shepard, 2017; Finkelstein, Hendren and Shepard, 2019).
} 
reported subsidies), take-up was lower than in the Basic Reminder group, consistent with consumers misperceiving subsidy benefits and facing transaction/hassle cost of purchase. ${ }^{7}$

We also find that the letter interventions on average induced healthier consumers into the market. We employ two measures of health risk-expected expenditures based on prior health care encounters, and a second measure based on claims incurred during the covered year following the intervention. We find consistent effects across the two measures. Conservative results suggest that the letter interventions lowered average spending risk by 5.1 percent, implying that marginal respondents to the letters were 37 percent less costly to insure than inframarginal enrollees. Part of the positive selection is driven by the entry of younger consumers, but most is driven by take-up among lower risk consumers conditional on age and region. Age and region are the only two variables that plans can use adjust premiums, implying that the positive selection resulted in greater risk pooling and potentially reduced adverse selection in equilibrium.

Finally, we estimate a simple consumer choice model, which allows for the presence of behavioral frictions in take-up to impact measured willingness-to-pay (WTP) for coverage. Reducing the cost of acquiring subsidy and plan information, and providing reminders to enroll, could raise measured WTP. On the other hand, the letters could make relative plan prices more salient, resulting in greater price responsiveness and lower WTP. We estimate that the information provided by the letters raises WTP for insurance by $\$ 25$ to $\$ 54$ per month. This is remarkable given that the intervention was a mailed letter, costing only $\$ 0.69$ cents. The "low touch" nature of the intervention, along with its large implied value, suggests the presence of residual behavioral frictions that hinder take-up. This is consistent with the low willingness-to-pay for insurance estimated by Finkelstein, Hendren and Shepard (2019). And while the availability of uncompensated care likely contributes to the gap between WTP and their medical costs of marginal enrollees, the value of the information from our letter intervention suggests behavioral frictions may also explain why measured WTP is so low.

These results highlight the importance of behavioral frictions-particularly hassle costs of enrollment and information search costs-in determining enrollment and average market risk. The effects of the relatively low cost and "low touch" interventions studied here motivate policies that further target these frictions, including more intensive outreach, simpler enrollment processes, and the use of defaults or

\footnotetext{
${ }^{7}$ As we discuss below, this result is also consistent with consumers exhibiting reference dependence utility.
} 
auto-enrollment. ${ }^{8}$ Importantly, we find a notable difference in risk selection for different subsamples, depending on their baseline level of information. This difference highlights how the marginal response to an intervention depends on the baseline risk selection and informational environment.

The rest of the paper proceeds as follows. Section 2 describes the ACA marketplace from the consumer's vantage point. Section 3 describes the field experiment, letter interventions and the study sample. In Section 4, we outline our empirical strategy for identifying treatment effects on enrollment and average market risk. In section 5, we present our main estimated treatment effects on enrollment and market risk. Section 6 presents a simple model describing how behavioral frictions can affect measured WTP for insurance coverage, and estimated changes in measured WTP in response to our letter interventions. Section 7 concludes with a summary of results and a discussion of policy implications.

\section{Background on the ACA Marketplaces and Enrollment Frictions}

A major provision of the ACA was the establishment of regulated insurance marketplaces, or "Exchanges," for the non-group and small group markets made up of individuals without health insurance coverage through a large employer or another public program. Given the complications of the individual market prior to the ACA-characterized by denials of coverage, complicated products, and low rates of enrollment-the ACA sought to improve affordability, competition and stability in the market through a number of regulations on premium setting, plan design and subsidy determination.

To make premiums more affordable to consumers with higher expected health care costs, insurers under the ACA can only vary premiums for a plan by age (and smoking, in some states other than California), but the ratio of premiums for the oldest to the youngest consumers cannot exceed 3:1. Insurers also cannot deny coverage to anyone that is eligible for participation in the market, a policy known as "guaranteed issue." ${ }^{9}$ In addition to regulations on how insurers can set prices, there are also standardizing rules on the plan benefit designs, to minimizing "cream-skimming," and to simplify

\footnotetext{
${ }^{8}$ See Shepard (2019) for recent research in the enrollment and risk effects of easing enrollment through autoenrollment mechanisms. And as of the submission of this manuscript, legislation was pending in California to require outreach and auto-enrollment into Covered California for a large segment of the population studied here (the "County Referred" group) (Senate Bill 260, 2019-2020 Regular Session).

${ }^{9}$ Given the evolution of risk over the life cycle, these types of pricing rules can increase consumer surplus (Handel, Hendel and Whinston, 2015); however, without other mitigating policies they can also lead to adverse selection and instability in the market (Geruso and Layton, 2017). To limit adverse selection, the law mandated that individuals be insured. The Tax Cut and Jobs Act of 2017 zeroed out the mandate penalty starting in 2019.
} 
consumer decision-making by minimizing search frictions. For example, all plans must be classified as one of five metal tiers corresponding to actuarial value. ${ }^{10}$

Numerous complexities remain in the ACA's active choice environment. To ensure that all households can afford coverage, the law also provides progressive premium and cost-sharing assistance. Generally, individuals in households with an income between 100 and 400 percent of the federal poverty level (FPL), and who do not have access to other affordable insurance options (such as employer-sponsored care or Medicaid) are eligible for an Advanced Premium Tax Credit (APTC) for plans sold on the Exchange. The APTC uses a complex formula, based on projected income and the distribution of premiums offered in a market. This complexity makes it difficult to anticipate or communicate how much each product will cost net of the premium subsidy. As a result, consumers generally need to use an online calculator or complete an insurance application to browse plans and compare their net-ofsubsidy prices, a process that requires time and effort. ${ }^{11}$

Surveys conducted by Covered California suggest that behavioral frictions may be large. Despite California's multi-faceted approach to outreach and marketing (Lee at al. 2017), many uninsured Californians do not understand what their subsidy is for coverage on the Exchange (Greenberg, 2017). And some remain unaware of their eligibility for Exchange coverage and premium subsidies, particularly consumers transitioning between the state Medicaid program and the exchange (Greenberg, 2017). The potential for these behavioral frictions to impede enrollment motivates efforts to raise awareness, and to reduce the hassle cost of enrollment. Moreover, efforts to increase enrollment may also have implications for market risk. On the one hand, policy-makers recognize the potential risk pooling benefits of increasing enrollment among healthier consumers for whom the cost-both financial and transactional-may exceed their demand for insurance. On the other hand, there is concern that easing enrollment among special enrollment populations may raise risk and destabilize premiums (Eyles and Handelman, 2016; Federal Register, 2017a, 2017b).

\footnotetext{
${ }^{10}$ Plans sold in the California non-group marketplace must adhere to standardized product designs, beyond actuarial value, including standardized cost-sharing and deductible profiles within metal tier. The impacts of informational interventions reported in this study should therefore be interpreted in the context of heightened standardization, designed to foster plan comparison and competition. In Massachusetts, standardization allowed consumers to better choose higher value plans (Ericson and Starc, 2016).

${ }^{11}$ Premium credits are reconciled at the end of the year once annual income has been realized. This means that even the complex prices determined during the year may change upon filing taxes (which occurs after all health insurance has already been purchased and consumed).
} 


\section{Study Sample and Interventions}

\subsection{Study Sample: The Covered California "Funnel"}

The sampling population for the study is the "Funnel" into Covered California, comprised of consumers that had an active determination of eligibility for Covered California 2016 coverage, but had not yet selected a plan. Consumers in this study entered the Funnel through two pathways:

The first source of the Funnel was households that applied directly to Covered California, were determined eligible to enroll (and, if applicable, eligible for subsidies), but never selected a plan. These consumers, who we henceforth refer to as "Open Enrollment Applicants" were self-selected based on interest in marketplace coverage by virtue of their applying to Covered California. ${ }^{12}$ After initiating the enrollment process, a household may not have chosen a plan for any number of traditional financial reasons, such as costs exceeding the benefits from coverage. Failure to follow-through on insurance purchase also could have been due to behavioral reasons unrelated to financial cost-benefit. For example, a household might have had difficulty choosing between plan options, been unaware or confused about their amount of subsidy support; or they could have planned to return later to complete the process, but have forgotten to enroll before the deadline. ${ }^{13}$ But based on having applied for coverage, Open Enrollment Applicants were aware of Covered California, and likely to have previously seen information about enrollment deadlines, plan options and potential availability of subsidy benefits.

The second source of the Funnel was prior enrollees from the state Medicaid program who experienced a change in their eligibility (for example, loss of eligibility due to an increase in income). These changes could have been initiated by the consumer reporting a change in circumstances (e.g. income) to the County, but could also have been initiated by a County performing periodic re-determination. Henceforth, we refer to this population as "County Referrals." Any household that entered the Funnel by county referral was sent a formal notice (letter) from their county informing them of their changed Medicaid eligibility and new eligibility to enroll in a plan through Covered California. Depending on their incomes and other eligibility conditions, these consumers may also have been eligible for subsidies through Covered California. Compared to Open Enrollment Applicants, County Referral households were

\footnotetext{
${ }^{12}$ These consumers may have visited www.CoveredCA.com and entered information themselves, or could have worked with various Covered California Certified Enrollers, including call center employees, licensed insurance agents, navigators, or other enrollment personnel certified by Covered California to provide consumer assistance. ${ }^{13}$ Additionally, some consumers may not have enrolled because they experienced a change in life circumstance that causes them to no longer require coverage through the marketplace (e.g. securing new employment that included a health coverage benefit).
} 
typically at an earlier stage in their engagement with the marketplace, and likely to have had less exposure to information about plan options, subsidy benefits, and subsidy determination.

Because information may serve different roles for these two populations, we conduct much of the analysis separately for Open Enrollment and County Referral samples, allowing us to better understand the mechanisms that drive the results. The total size of the Funnel prior to open enrollment was 153,146 households of which 64 percent were County Referrals, and 36 percent Open Enrollment Applicants.

\subsection{Sample Selection for Randomized Control Trial}

The prior section describes the full set of households in the Funnel who were deemed eligible for the study at the time of treatment assignment. For budgetary reasons, we reduced the total sample to 126,182 randomly selected households from the full Funnel to be in the study. ${ }^{14}$ These households were then randomized into the 5 study arms using the method described in Section 3.4. Since the time of the treatment randomization, we became aware that some households were not eligible to enroll in Covered California, or did not have valid addresses. We excluded these households to create the final study sample. Because treatment assignment was random, these ex post exclusions have an identical effect on all study arms in expectation. We report balance tests within this final sample in Section 3.4.

First, we excluded households for whom administrative data reported invalid ages for any member, as invalid ages would have led to incorrect or missing premiums reported in subsidy-reporting letters. ${ }^{15}$ Next, we excluded households who had incomes below 100 percent of FPL. These households were generally ineligible for subsidies in ACA exchanges, and hence were unlikely to enroll in an exchange plan. We also dropped households that the postal service reported as having moved before the experiment, and for whom we did not have a current mailing address. Finally, we excluded County Referral households who were deemed ineligible for subsidies. ${ }^{16}$

\footnotetext{
${ }^{14}$ The 126,182 households were randomly selected in two phases. To guarantee sufficient time to compute subsidies and print personalized letters for a sufficient sample by the deadline, we randomly selected 100,000 households from the Funnel sample as of one month before the enrollment deadline. From the households who entered the Funnel over the following two weeks, we randomly sampled $(26,182)$ additional households until we exhausted our budget. Note, because later entrants to the Funnel had higher baseline enrollment, take-up rates for the "Initial Budgetary Exclusion" group are slightly higher than that of the initial Funnel sample ("All”), reported in Appendix Table 1.

${ }^{15}$ Enrollee ages are based on year of birth. Specifically, we excluded $0.5 \%$ of households with any member that was 100 years or older, or in very rare instances had a negative reported age.

${ }^{16}$ After implementing the original intervention, it was determined in consultation with state program administrators that many of these consumers were simultaneously being evaluated for other Medicaid coverage options that existed prior to the ACA. For those who qualified-which would have resulted in the consumers being
} 
The final sample size after applying these exclusions is 87,394 households. These exclusions and their impact on the sample size are reported in Appendix Table 1. Again, although these exclusions were made after the initial randomization, their impact on each study arm is the same in expectation. ${ }^{17}$

The average age of the study sample is 37 years old and the average income level is 215 percent of FPL. In general, we find the demographic composition of the study sample to be roughly a mix of the uninsured population in California and the Covered CA enrolled population, which is unsurprising given the Funnel definition stated in the prior section. See the written Appendix for a more detailed comparison of these populations.

\subsection{Experimental Letter Interventions}

Subjects in the study were randomized into one of five arms: a control arm (arm 1) or one of four intervention arms. Individuals in the control arm received no direct communication beyond the generic outreach and state-wide marketing activities used by Covered California for all consumers, representing status quo interaction with Funnel consumers. ${ }^{18}$ The intervention arms received the following letters: ${ }^{19}$

- Basic Reminder (Arm 2): Reported the open enrollment deadline, and the Covered California website and telephone number where they could shop for plans.

- Subsidy and Penalty (Arm 3): Reported basic reminder information (Arm 2) plus the household's estimated monthly subsidy and tax penalty, based on their reported income and household size.

- Price Compare (Arm 4): Reported the content of Arms 2 and 3, plus a table listing the Silver and Bronze plans offered in their market, with their net-of-subsidy premium. ${ }^{20}$

- Price and Quality Compare (Arm 5): Reported the content of Arm 4, but the table also included plans' quality rating. Quality ratings were based on Consumer Assessment of Healthcare Providers and Systems (CAHPS) measures.

found ineligible for marketplace subsidies-these programs were more financially beneficial than purchasing unsubsidized plans through Covered California.

${ }^{17}$ We also replicate all analyses using the full post-randomization pre-exclusion sample of 126,182 . As expected, we find that control group take-up is slightly lower in this sample than in the final study sample, given the inclusion of households who are unlikely to take-up; but estimated treatment effects and patterns of heterogeneity are nearly identical to those observed for the final study sample. Results are available upon request.

${ }^{18}$ Consumers in all arms, including the control arm, could still have received information through general advertising, such as Covered California sponsored newspaper, radio, and television advertisements, or outreach conducted by third parties.

${ }^{19}$ Letters in all treatment arms were double sided, accordion style letters. When opened, the large postcard sized mailer would unfurl into a four post-card length letter. One side of the letter was uniform across all four letter interventions, and reminded the study subject in simple bold typeface about how to enroll, and the January 31, 2016, enrollment deadline. The opposite side of the unfurled letter varied according to assigned treatment, each targeting a specific mechanism, below. Households that indicated Spanish as their primary language received the letters in Spanish. Templates of each letter are included in the Appendix.

${ }^{20}$ For low-income consumers eligible for the "enhanced" Silver plan with cost-sharing reductions, the table in the letter reported only Silver plans. 
Each of the four letter interventions was designed to reduce one or several behavioral frictions that potentially impede take-up:

Inattention and psychological cost of remembering: Open Enrollment applicants had just a few weeks earlier submitted income information and received an eligibility determination, and were aware of existence of Covered California and its enrollment process. For these consumers, the Basic Reminder letter provided a reminder that targeted inattention, or the psychological cost of remembering to enroll (as opposed to providing fundamentally new information). ${ }^{21}$

Lack of Awareness about Covered California: Consumers who enter the Covered California Funnel through County Referrals (primarily from Medicaid disenrollment) were likely at an earlier stage of engagement with Covered California for insurance coverage. In many cases, they may not have taken any direct action personally, and may have been less informed about the products and prices available to them in Covered California. For this subpopulation, the Reminder Letter targeted both program awareness and inattention.

Lack of Awareness of Subsidy and Penalties: Conceptually, we view lack of awareness as rooted in search costs. As mentioned in Section 2, subsidy eligibility, as well as subsidy and penalty levels, are based on a complex formula and not easily determined. To reduce the cost of acquiring this information, the subsidy-reporting letters (Arms 3-5) reported total estimated annual subsidies and penalty for all policy members reported on their initial application. ${ }^{22}$

Lack of Awareness of Plan Attributes: Previous studies have shown that making plan attributes more salient leads consumers to switch to lower cost plans (Abaluck and Gruber, 2011; Kling et al. 2012) or to higher value plans (Ericson and Starc, 2016). The salience reduces the cost of acquiring plan attributes and making plans easier to compare, and suggests that assisting consumers in acquiring this information may also improve take-up. The Price Compare Letter lowers the cost of learning about plan availability and the consumer's net-of-subsidy premiums for plans. Moreover, evidence suggests that consumers demand higher value, not just lower cost (Blumberg and Buettgens, 2013; Ericson and Starc, 2016).

\footnotetext{
${ }^{21}$ Simple reminders with no personalized information have been shown to improve adherence in other settings, such as paying parking tickets (Heffetz, O'Donoghue and Schneider, 2016). Moreover, peak enrollment typically occurs just prior to enrollment deadlines, indicating that procrastination may allow inattention to further impact enrollment. See Ericson (2017) for a discussion about the interactions between inattention and procrastination. ${ }^{22}$ Subsidy and penalty amounts reported in the letter were based on income and family size on the household application and used for the determination of eligibility by Covered California.
} 


\subsection{Randomization}

We assigned each household in the study sample to one of the five study arms, using stratified randomization. This method ensured that we had balanced the sample on observable characteristics, and reduced variation across treatment groups due to randomness. The observable characteristics we used for stratification were income category $(<150,150-200,200-250,250-400,>400$ percent of FPL, or missing), race category (Latino or Black vs. all other), Spanish language preference, email eligible, and whether the household used an enrollment delegate. The unit of stratification was the intersection of each of the above five characteristics, creating 80 stratification units. Household within each of the 80 strata were then randomly assigned to one of the five study arms.

As described in Section 3.2, we imposed several exclusion restrictions after the randomization. Randomization ensured that the study arms in the final sample are balanced in expectation. Table 2 reports how observable characteristics of the final study vary by treatment arms. For all characteristics, a joint F-test of equality across arms cannot be rejected at the 0.05 level. The $p$-value for age is marginally significant (at $\alpha=0.1$ ), but as seen in the last column, we cannot reject that average age in the control arm is the same as in all treatment arms combined. ${ }^{23}$ This is evidence that treatment assignment is unlikely to be correlated with unobservable characteristics that impact enrollment.

\section{Empirical Strategy}

\subsection{Data}

We used three administrative data sources for this study. First, data on applications and enrollment from Covered California permitted us to track plan selection, payment and cancelations throughout 2016. Households were considered to have taken-up insurance if they paid premiums for a plan selected before the open enrollment deadline.

We also used two sources of data on health spending risk: risk scores from Office of Statewide Health Planning and Development (OSHPD) Patient Discharge Data and Emergency Department Data, derived using the Chronic Illness and Disability Payment System (CDPS), and Verisk risk scores reported by IBM Watson Health (formerly Truven). CDPS risk scores are based on 2015 hospital and emergency

\footnotetext{
${ }^{23}$ Because the unit of observation is the household, age is the average age across all members of the household's policy. The variance in mean household age across households is naturally lower than the variance across individuals' age, resulting in a correspondingly lower $p$-value.
} 
department encounter data, and provide a measure of prospective health spending risk for the 2016 covered year. CDPS risk scores were available for all study participants, irrespective of take-up in study year 2016. IBM Watson Health's Verisk risk scores are based on diagnoses inferred from complete medical and prescription drug claims experienced during the 2016 enrollment year, following the intervention. As such, they reflect concurrent expected health spending based on claims incurred during the study year, and are only available for consumers who took-up coverage in 2016.

\subsection{Estimation Strategy}

\subsubsection{Experimental Impacts on Take-up}

Our main outcome of interest is take-up of Covered California insurance. We exploit the random assignment to treatment arm to identify the causal impact of the four letter-based interventions on average take-up rate. We estimate:

$$
\begin{gathered}
\text { Takeup }_{i}=\beta_{0}+\beta_{1} \text { Reminder }_{i}+\beta_{2} \text { SubPen }_{i}+\beta_{3} \text { PriceCompare }_{i}+ \\
\beta_{4} \text { PriceQualCompare }_{i}+x_{i}^{\prime} \Gamma+\epsilon_{i}
\end{gathered}
$$

In most specifications, we include a vector of household level characteristics, $x_{i}$, controlling for family size, number of kids, age, race, language preferences, marital status, Covered California's age-based community-rating premium ratio, and household income (as percent of the FPL). If balance is achieved by the randomization, their inclusion should not markedly impact estimated treatment effects, and serve primarily to increase precision.

Because all letter interventions include a reminder about the deadline and Covered California contact information, the effects of Subsidy+Penalty (arm 3), and the effect of the two plan comparison letters (arms 4 and 5), are estimated as the additional impact beyond that of the Basic Reminder letter, captured by $\beta_{1}$. In some specifications, we collapse the three arms that report subsidies to differentiate between the basic reminder letter from letters that report personalized subsidy information. Where meaningful, to estimate the average effect of all letter interventions, we report results when all four interventions arms are combined into a single indicator variable.

We also examine two key sources of heterogeneity: income and baseline health risk. Income may be related to willingness-to-pay for insurance, and determines subsidies. Additionally, choice frictions and other search costs may differ by socioeconomic status. Lower income individuals may face greater barriers to acquiring information, comparing plans, or following through on purchase, due to language barriers, lower education, or stress-related cognitive overload (Mani at al., 2013; Mullainathan and 
Shafir, 2014; Bhargava, Loewenstein and Sydnor, 2017). On the other hand, higher wage-based value of time among higher-income consumers could imply higher time cost of search. To test for heterogeneous treatment effects, we estimate equation (1) including interactions between treatment indicators and baseline household income. And to the extent that these information acquisition costs cause consumers to form incorrect beliefs about their subsidies in ways related to income (particularly given its steep progressivity), then the subsidy-reporting letters may have differential effects on take-up by income.

We also estimate equation (1) including interactions between treatment arm and baseline risk, as measured by the prospective CDPS risk score (which is available for the full study sample, not just those who took-up coverage). Positive coefficients on interactions between treatment assignment and baseline risk would imply that the marginal respondent to letters on average had higher spending risk. ${ }^{24}$

\subsubsection{Experimental Impacts on Market Risk}

To estimate explicitly the impact of the letter interventions on average risk of the study sample, we regress consumers' health risk on treatment assignment, conditional on take-up, as in:

$$
\begin{gathered}
\text { Risk }_{\text {Score }}=\beta_{0}+\beta_{1} \text { Reminder }_{i}+\beta_{2} \text { SubPen }_{i}+\beta_{3} \text { PriceCompare }_{i}+ \\
\beta_{4} \text { PriceQualCompare }_{i}+x_{i}^{\prime} \Gamma+\epsilon_{i}
\end{gathered}
$$

The coefficients on the treatment arms in equation (2) capture the impact of the interventions on average risk of the study sample. Along with the estimated treatment effect on take-up, the impact on average risk can be used to estimate the average risk across respondents to the treatment. ${ }^{25}$ Given the smaller sample sizes in risk analyses conditional on take-up, we will report specifications where we combine the three subsidy-reporting letter arms into a single group, Subsidy Arms.

For the treatment effects in (2) to capture changes in average risk of the covered study sample faced by plans, we weight the households by the number of months they are enrolled. This is to ensure that we do not over or underestimate the impact of the letters on average risk, if enrollment duration of

\footnotetext{
${ }^{24}$ In a separate specification, we interacted treatment arm with age. Carriers are allowed to factor in age when setting premiums. Because the age-expected spending profile is steeper than the ACA's 3-to-1 ratio of the highest and lowest age-based premiums (Blumberg and Buettgens, 2013), differential take-up among younger enrollees may still lower overall premiums. We find differential take-up among younger enrollees (results are available upon request). Below, we show that the majority of the positive risk selection is conditional on age therefore unpriced. 25 If the interventions also caused some consumers to decrease take-up, then this average risk would correspond to the average of all marginal respondents, including households persuaded and dissuaded by the letters to enroll.
} 
marginal respondents to treatment-whether healthier or sicker-differs from inframarginal enrollees. We also explicitly test for differences in enrollment duration by treatment arm, conditional on take-up.

\section{Results of Letter Interventions on Take-up and Risk}

\subsection{Average Treatment Effects on Take-up}

Table 3 reports the overall impact on take-up, by letter intervention. The average increase in take-up across the four treatment arms, compared to the control, is 1.3 percentage points. This is equivalent to an average increase by 16 percent above the control group take-up rate of 0.081 . Overall, there were no differences in take-up across the letter interventions, a finding we revisit in sub-group analyses.

The average impact for the full sample is essentially unchanged after controlling for an extensive list of household and primary policy holder characteristics (Column 2 vs 1), listed in Section 4.2.1, and in the table notes. We also find take-up declined steadily with household income, likely due to the phase out of the premium subsidies, which by statute decline at a much higher rate than income rises. ${ }^{26}$

As described in section 3.1, Open Enrollment and County Referral applicants differed in their baseline awareness of plan options, prices and subsidies available to them through Covered California. ${ }^{27}$

Therefore, we report estimates separately by Open Enrollment Applicant and County Referral samples, in columns 3 through 8 . Consistent with differences in baseline awareness of the marketplace, control group take-up rates are over 3.5 times higher for the Open Enrollment application sample.

For the Open Enrollment sample, the overall impact of the letter interventions is 1.6 percentage points, or roughly a 13 percent increase (relative to a control mean of 0.127 ). We interpret the Basic Reminder Letter-Arm 2-in the Open Enrollment Applicant sample as addressing inattention to the deadline, given that the information provided in the reminder letter duplicated information consumers had already been exposed to during their initial active registration. The Basic Reminder increased enrollment

\footnotetext{
${ }^{26}$ For example, the average single-policy holder at 133 percent of FPL would face an annual net-of-subsidy premium of $\$ 510$; whereas with three times that income, right below 400 percent of FPL (at the threshold of subsidy eligibility), the average annual net-of-subsidy premium would be $\$ 4,600$, or nearly 10 times higher. ${ }^{27}$ County Referral households likely included a mix of consumers at different stages of engagement with Covered California: some may have experienced a change in Medicaid eligibility and been counseled about Covered California options by a county eligibility worker; others may have received a formal notice of changed Medicaid eligibility for the first time, and may not yet have realized Covered California was an option; others may not have been seeking marketplace coverage (e.g. due to having since received job-based coverage); while others may have resembled Open Enrollment households in that they may have previously applied through CoveredCA.com.
} 
by roughly 13 percent. Notably, the impact of interventions that report subsidy and plan characteristics are not significantly different than for the Basic Reminder. In the next subsection, we examine heterogeneity in the relative effect of the letter interventions, by income.

For the County referral sample, the letter interventions increased enrollment by nearly 17 percent (relative to control group mean of 0.036). The treatment effect is slightly larger than for the Open Enrollment sample, in part due to the relatively low baseline enrollment rates in the County Referral group. The low baseline take-up rate is consistent with the prior beliefs that county-referred applicants were at an earlier stage of engagement in the Covered California application process, allowing for larger potential impacts of information. ${ }^{28}$ Indeed, we find that providing additional information beyond the reminder leads to higher take-up. The reminder letter increased take-up by (a statistically insignificant) 11 percent; providing additional subsidy information increased enrollment by 19 percent. While the differences across the letter arms are not statistically different, the patterns are consistent with lack of information impeding take-up among the County Referral sample, and that providing more information-particularly personalized information about premium subsidies-further reduced information barriers.

\subsection{Heterogeneous Treatment Effects by Income}

Figure 1 illustrates how take-up rates vary by income, separately for the control, the Basic Reminder arm and the subsidy-reporting arms. For the Open Enrollment Applicant sample, in panel (a) of Figure 1, take-up rates for the subsidy-reporting arm falls more steeply than the control and basic reminder arms. At low incomes, take-up is higher for the subsidy-reporting arms than the Basic Reminder arm. But as incomes rise, take-up rates for the subsidy-reporting arms fall below that of the Basic Reminder arm.

Table 4 formalizes this by estimating the interaction effects between treatment assignment and income. For completeness, we present these results using a linear specification of income (columns 1-3) and categorical groups (columns 4-6). Consistent with Figure 1, we find that at the lowest incomes, reporting subsidies results in marginally significant but slightly higher take-up than providing the basic reminder alone. This is most evident in the Open Enrollment sample (column 5). Surprisingly, as incomes rise for the Open Enrollment sample, the take-up rates for the subsidy-reporting arms fall steadily (as seen in column 2), and to levels that are lower than in the Basic Reminder arm. The relative effects sizes are

\footnotetext{
${ }^{28}$ Note that these take-up rates correspond to the enrollment rate of the Open Enrollment and County Referral Applicants in the study sample control group, which are lower than the overall program take-up rate in the marketplace-eligible population as whole.
} 
most evident in columns 4-5, where the treatment arms are interacted with income group indicator variables. As incomes rise, take-up rates for the subsidy-reporting arms fall below that of the Basic Reminder arm, despite enrolling consumers in the Basic Reminder arm eventually observing the same subsidy information provided in subsidy-reporting letters. ${ }^{29}$

This pattern is consistent with Open Enrollment Applicants with higher incomes incorrectly believing their subsidies were higher than in reality; and, in response to updated information, they were less likely than otherwise similar consumers in the Basic Reminder arm to re-initiate and complete the enrollment process. Moreover, the timing of the information appears to matter: in addition to having incorrect priors, consumers appear to exhibit a fixed time or hassle cost of re-initiating the enrollment process. Consistent with Currie (2006), fixed time or hassle costs represent behavioral transaction costs, which, along with the financial cost of plans, could contribute to a total cost of purchasing insurance. If so, households that received a negative update about premiums after incurring the transaction cost of reinitiating the enrollment process (as would be the case for households in the Basic Reminder arm) may have enrolled at higher rates than households that received a negative subsidy update before reinitiating the enrollment process (as would be the case in the subsidy-reporting arms). ${ }^{30}$

\subsection{Heterogeneous Treatment Effects by Spending Risk}

To estimate the differential take-up by health risk, we estimate equation (1) including interactions between treatment assignment and log health spending risk. Results are reported in Table 5. All specifications control for region and interactions between treatment arms and the consumer age rating

\footnotetext{
${ }^{29} \Delta_{1}$, reported at the bottom of the Table 4, reports the additional effect of the subsidy reporting letters over the basic reminder at incomes below 180 percent of FPL. $\Delta_{2}$ reports the same difference in treatment effects for the 250-400 percent FPL segment. The drop in the relative effect of the subsidy reporting letters over the reminder letter between consumers in higher income groups and the lowest income group (below 180 percent of FPL) is reported as $\left(\Delta_{2}-\Delta_{1}\right)$.

${ }^{30}$ Intriguingly, these patterns are also consistent with reference-dependence utility, as formalized by Koszegi and Rabin (2006). Specifically, Koszegi and Rabin (2006) model an "attachment effect," where an increase in the likelihood of buying (e.g. due to beliefs among higher income consumers in the Basic Reminder arm that net-of subsidy prices would be low) increases a sense of loss of not buying, which then increases the willingness to buy at a higher price than initially expected (as compared to higher income consumers in the subsidy reporting arms who are shown their higher net-of subsidy prices prior to shopping). Without additional interventions that shift beliefs about expected prices, or data on plan searching-through insurance brokers or visits to the Covered California website-we are unable to distinguish between transaction costs and reference dependence. However, the role of inattention (shown by the impact of the Basic Reminder letter in Table 3 as well as the cost of obtaining information about program benefits (shown by the differential impact of subsidy-reporting letters by income, in Table 4), suggests that fixed costs of remembering to enroll and enrolling at least partly explain this pattern.
} 
factor used for age-based premium pricing. Thus, any heterogeneous take-up risk will represent selection on spending risk that plans are unable to price in.

Four major patterns are evident. First, the treatment effects of the letters on take-up are markedly stronger among healthier consumers. In the following section, we examine explicitly the impact of the letter interventions on average risk. Second, the differential treatment effect among healthier consumers is concentrated in the Open Enrollment sample, who are generally aware of the existence of health plan and premium subsidies on the Exchange. Consistent with a simple adverse selection model with behavioral frictions, sicker Open Enrollment applicants with higher demand for coverage may have already incurred the frictional costs associated with shopping and enrolling; and by lowering these frictions, the letters may have disproportionately induced marginally healthier consumers into the market. By contrast, if the County Referral applicants were typically less aware of marketplace options and had a lower overall baseline take-up rate, the letter interventions may have induced both healthy and sick consumers into the market.

Third, the positive health selection effects of the letter intervention are concentrated among lower income Open Enrollment consumers. This suggests that lower income individuals may face greater hassle cost and frictions associated with remembering to enroll, choosing a plan, and enrolling by the deadline. If so, letters that reduce these frictions would magnify the overall enrollment effects among healthier consumers.

Finally, we examine whether the differential treatment effect by health risk is explained by heterogeneous treatment effects along observable dimensions that plans are permitted to price innamely, age factors and region. If, for example, the treatment selection effects are embodied in differential treatment effects by age, then much of the healthier risk response would be reflected in the lower premiums received by plans for younger enrollees. To examine this, we repeat the regression specifications of Table 5, but do not include the interactions between treatment arm and the consumer age rating factors used for age-based premium pricing. Results are reported in Appendix Table 2. Dropping the age rating factor controls leaves the estimated coefficients on the interaction terms between treatment and baseline risk largely unchanged, implying that the vast majority of the positive risk selection induced by the interventions is not explained by differential take-up by age, but rather by unpriced health risk conditional on age. Below, we directly estimate the effect of the intervention on average risk, and decompose the effects into priced and unpriced factors. 


\subsection{Impact on Health Spending Risk}

Figure 2 shows the distribution of log risk for the Open Enrollment sample, reported for both the prospective and concurrent measures of risk. The distribution of risk among treated households is shifted to the left, as compared to the control group, where the shift is more pronounced among low income consumers. In contrast, there is no obvious shift in risk for the County Referral sample.

Table 7 reports regression estimates of treatment effects on average prospective CDPS risk scores (equation 2). All regressions are weighed by the number of months each household held coverage, to reflect average risk experienced by plans. ${ }^{31}$ Overall, we find that the letter intervention led to a 5.1 percent decrease in average risk. This implies that the average risk of the marginal respondent to the letter interventions was 37 percent of the expected expenditure risk of the average inframarginal enrolled consumer in the study sample. ${ }^{32}$

Consistent with the heterogeneous take-up results by risk reported in Table 5, we find that most of the improvement in risk induced by letter interventions appear in the Open Enrollment sample, and among lower income consumers. Note that in Panel A, we do not control for age rating factors or region, dimensions along which plans can vary premiums. In Panel B, we do control for the age rating and indicators for the 19 rating regions. Controlling for these factors mutes the average effect. But differences across Panels A and B imply that only 15 percent of the reduction in average risk is explained by factors plans can use to vary premiums. 85 percent of the lower health risk induced by the letter interventions can be explained by improved risk along dimensions that cannot be priced in.

Recall that the CDPS risk scores are a measure of prospective risk, and are based on complete in-patient hospital and emergency department claims observed in any health facility in the state of California from the previous calendar year, irrespective of insurance status. The CDPS risk scores therefore are based on comprehensive encounters in hospitals, and available for the entire study sample, allowing for the heterogeneous treatment effect analysis reported above. However, the CDPS scores in this study do not capture encounters in out-patient settings. This may exacerbate a common concern of many risk

\footnotetext{
${ }^{31}$ Weighting has little effect on the estimated impact on average risk. We explicitly test for differences in coverage duration, by treatment arm. We find that enrollees in the letter intervention arms are covered for a negligible and statistically insignificant 3.9 fewer days, compared to a control mean of 8.4 months. For the Open Enrollment (County Referral) sample, intervention arm enrollees are covered 1.6 (10.2) days fewer, compared to a control mean average of 8.4 (8.5) months. Results are reported in the Appendix.

${ }^{32} \mathrm{~A} 5.1$ percent decrease in average risk, given a 16 percent enrollment increase, implies an average risk among marginal responders that is $0.630=(((1-0.051) * 116-100) / 16)$ of the average risk of inframarginal consumers.
} 
scores - that they may not adequately account for differences in coverage status when predicting insured spending risk. For example, apparently healthy respondents who had been uninsured in 2015 may have had pent up demand when enrolling in the study year, leading to over-estimated positive CDPS risk treatment effects of the letters. On the other hand, healthier respondents who were previously uninsured may consume less hospital and emergency department care when covered by a plan that manages diseases.

To address this potential limitation of the CDPS score, we use a second measure of risk based on complete realized claims of consumers enrolled in Covered California during the study year. ${ }^{33}$ We reestimate equation (2) on all enrolled consumers using this concurrent risk score. Estimated coefficients capture difference in average risk, by treatment assignment. ${ }^{34}$

Table 8 reports the results. We find remarkably consistent effects across the two measures of risk. Overall, the letters led to a decrease in average risk by 6.3 percent. This implies that the average risk of the marginal respondent to the letter interventions was 46 percent of the expected expenditure risk of the average inframarginal enrolled consumer in the study sample. ${ }^{35}$

Here, too, the improved risk is primarily driven by healthier risk selection in the Open Enrollment sample, particularly among lower income consumers. For the Open Enrollment sample, the letters result in a 10.6 percent reduction in average risk. Controlling for enrollee' ACA age rating and region of residence-the factors plans are able to price into premium-cuts the positive risk effect by 37 percent, suggesting that 63 percent of positive risk selection effect would not be priced in. The implied 6.7 percent reduction in unpriced-in risk among Open Enrollment consumers is consistent with the 5.1 risk percent reduction estimated using the CDPS risk score.

\footnotetext{
${ }^{33}$ Risk scores based on study year claims will naturally reflect both underlying health risk and the enrollees' choice of plan, due to steering and cost sharing. This concern is similar in principle to the concerns about the CDPS risk scores, albeit less severe. We also investigate whether letter interventions led to differential take-up across plan metal tiers and plan type. We find that the letter interventions do not lead to differences in choice of plan metal tier or in choice of HMO or EPO plans. We do find that the consumers who received star quality rating (those randomized to intervention arm 5 ) were slightly more likely to choose a higher quality plan, but this effect was small and marginally significant. Results are available upon request.

${ }^{34}$ Concurrent risk scores were reported to us by IBM Watson at the individual level, not household level as with the individual-weighted CDPS scores. Regressions using the concurrent scores were thus run at the individual level. ${ }^{35} \mathrm{~A} 6.3$ percent decrease in average risk, based on a 16 percent enrollment increase, implies an average risk among marginal responders that is $0.543=(((1-.063) * 116-100) / 16)$ of the average risk of inframarginal consumers.
} 
The concurrent risk scores also show larger positive risk effects of the subsidy reporting letters as compared to the basic reminder, consistent with patterns observed for the CDPS risk score. This suggests that marginal respondents to a simple reminder were healthier than the average in the control group; and that letters that additionally reported generous subsidies induced even healthier consumers into the market, in line with an adverse selection model with behavioral frictions in enrollment.

Finally, the letter interventions generated statistically insignificant effects on average risk within County Referral sample, similar to results using the prospective CDPS risk score. The letter interventions evidently induced both healthy and sicker risks into the market. When contrasted with the effect of the letters on health risk among the Open Enrollment enrollees, this pattern suggests that prevailing levels of consumer awareness and prevailing selection into the market interact with information interventions to influence the impact of information interventions.

\section{Behavioral Frictions and Willingness-to-Pay for Insurance}

In this section, we introduce a parsimonious model of how behavioral frictions can impact take-up decisions and measured willingness-to-pay (WTP). Our first objective of the model is to demonstrate how measured WTP for insurance may be impacted by frictions. Second, we use this model to translate our experimental results into the dollar-valued reduction in consumer costs targeted by the intervention. Assuming that the letter interventions do not directly alter consumers' underlying WTP for coverage, the value of the letters can be interpreted as changes in measured WTP for available coverage. ${ }^{36}$ In both the model and estimation, we use the utility from the premium subsidy (APTC) to convert expected utility into monetary units of WTP.

6.1 Model of Frictions in Insurance Demand

\footnotetext{
${ }^{36}$ We distinguish between underlying WTP for risk protection and measured WTP for available coverage. We view underlying WTP as reflecting a fundamental demand for insurance. Misperceptions about health expenditure risk or the value of insurance constitute a source of behavioral bias, and may affect underlying WTP. See Moore and Healy (2008) for a review of the literature on misperceptions about the probability of negative events. This study takes underlying WTP as given, and quantifies the changes in WTP, as measured by demand estimation, in response to experimentally-induced reductions in frictions associated with the enrollment process (e.g. hassle costs of remembering to enroll, the search costs of obtaining information about subsidies, plan attributes and plan prices). Misperceptions in underlying financial risks could also be targeted by interventions-say, by providing information about the financial risks faced by consumers-but were not the focus of this study.
} 
Consider household $i$ with monthly subsidy (ATPC) $\tau_{i}$. The indirect utility $u_{i}$ of insurance relative to remaining uninsured is:

$$
u_{i}=I_{i}-I_{i}^{p}-c^{\text {Memory }}-c^{\text {Search }}+\alpha_{i} \tau_{i}+\varepsilon_{i}
$$

In this specification, $I_{i}$ represents the utility of all insurance plans (excluding premiums) available to the household given their zip code, ${ }^{37}$ and $I_{i}^{p}$ is the disutility of all plan premiums. ${ }^{38}$ Equation (3) departs from a canonical specification of indirect utility in its inclusion of friction parameters. $c^{\text {Memory }}$ represents the mental cost of remembering to enroll. This friction is targeted explicitly by the Basic Reminder letter, the content of which is included in all intervention letters. $c^{\text {Search }}$ represents information search costs of learning about one's subsidy level, which is targeted by subsidy-reporting letters. $\varepsilon_{i}$ is the idiosyncratic utility of having insurance and follows a mean-0 logistic distribution. The household takes up insurance if the indirect utility $u_{i}$ exceeds 0 . In principle, other frictions could affect take-up-e.g. the hassle cost of enrolling in a plan-but are not explicitly modeled here. ${ }^{39}$ For this reason, the estimated value of our letters can also be thought of as a lower bound on the dollar denominated cost of frictions associated with the enrollment process.

In addition, we allow $\alpha_{i}$, the effect of subsidies $\tau_{i}$ on utility, to depend on how informed each consumer is about the level of subsidies. We model this friction in a reduced-form way such that:

$$
\alpha_{i}=\alpha_{0}-\tilde{\alpha} * 1\{\text { i imperfectly informed }\}
$$

$\alpha_{0}$ captures the effect of the subsidy on take-up for a fully informed consumer, and $\tilde{\alpha}$ represents a consumers' residual misinformation following any efforts to become more informed, including exerting search costs $c^{\text {Search }}{ }^{40}$ We highlight three types of consumers to illustrate the role of these frictions in

${ }^{37} I_{i}$ can be thought of as the "inclusive value" derived from a plan choice framework as $I_{i}=E\left[\max \left\{u_{i k}\right\}\right]$ where $u_{i k}$ is the utility of each individual plan. Hence, it includes the values of plan attributes such as provider networks.

${ }^{38}$ Note this form of $I_{i}$ and $I_{i}^{P}$ assumes additive separability in the utility of plans and plan premiums. In this sense, it is a reduced-form representation of the true indirect utility of the bundled choice set $E\left[\max \left\{u_{i k}-\alpha_{0} p_{i k}\right\}\right]$.

${ }^{39}$ Consumers may face additional frictions and search costs. For example, consumers may face high hassle costs of enrolling in a plan, apart from remembering to enroll and to compare plans and obtaining true prices. As our interventions do not specifically target the ease of enrolling, we do not explicitly model that here, but this framework could easily be adapted to include enrollment hassle costs.

${ }^{40}$ For the present purpose, we present a simplified model where all "uninformed" consumers face the same residual friction. In reality, the effect of subsidies could be consumer specific, such that $\alpha_{i}=\alpha_{0 i}-\widetilde{\alpha_{l}}$. Moreover, endogenous effort to incur the cost of becoming informed could depend on unobserved heterogeneous demand for insurance, e.g. risk. Similarly, $c^{\text {Memory }}$ and $c^{\text {Search }}$ may be consumer-specific, and efforts to reduce them may be correlated with risk and income. The model could then endogenize effort to illustrate the microfoundations of adverse selection, and the patterns of positive selection we observe in response to reductions in frictions. As the 
estimating the expected value of insurance in dollars, i.e. the expected WTP: 1) the baseline case where consumers exhibit both the hassle costs of remembering to enroll and informational search costs; 2 ) consumers who face search frictions but are not subject to hassle costs of remembering to enroll; and 3) consumers who face no frictions and are fully informed, such that $c^{\text {Memory }}, c^{\text {Search }}$, and $\tilde{\alpha}$ all equal zero. Based on common "revealed preference" frameworks, these three environments would generate different values for measured WTP for insurance. Using the notation in equation (3), expected measured WTP for coverage in the three cases is:

$$
\begin{gathered}
W T P^{\text {All Frictions }}=\frac{I_{i}-c^{\text {Memory }}-c^{\text {Search }}}{\alpha_{0}-\tilde{\alpha}} \\
W T P^{\text {Search Frictions Only }}=\frac{I_{i}-c^{\text {Search }}}{\alpha_{0}-\tilde{\alpha}} \\
W T P^{\text {Frictionsless }}=\frac{I_{i}}{\alpha_{0}}
\end{gathered}
$$

The differences in measured WTP due to eliminating the cost of remembering to enroll; and the difference in measured WTP due to eliminating both memory and information search costs are:

$$
\begin{aligned}
& \Delta W T P(\text { Remind }) \equiv W T P^{\text {Search Frictions Only }}-W T P^{\text {All Frictions }}=\frac{c^{\text {Memory }}}{\alpha_{0}-\widetilde{\alpha}}, \\
& \Delta W T P(\text { Inform }) \equiv W T P^{\text {Frictionsless }}-W T P^{\text {Search Frictions Only }}=\frac{c^{\text {Search }-\frac{\widetilde{\alpha}}{\alpha_{0}} I_{i}}}{\alpha_{0}-\widetilde{\alpha}} .
\end{aligned}
$$

These equations highlight two key results. First, removing these frictions can have an ambiguous effect on measured WTP. Removing the memory cost (by, say, providing effective reminders) will increase measured WTP. However, informing consumers of subsidy and plan information can have an ambiguous effect on measured WTP even if information search costs are non-negative. This is because the second term in the numerator of $\triangle W T P$ (Inform), $\frac{\widetilde{\alpha}}{\alpha_{0}} I_{i}$, can offset the first term. This second term represents the effect of updating the consumer about the subsidy level, and by changing $\alpha$, it affects the overall

present purpose of this framework is more simply to estimate how WTP changes in response to reductions in frictions, we abstract from this richness. 
WTP for insurance. For example, if more salient net-of-subsidy price information effectively makes consumers more price sensitive in enrollment decisions, measured WTP would decrease. ${ }^{41}$

Second, without accounting for behavioral frictions, an econometrician using demand estimation to measure WTP for available plans would confound underlying WTP for insurance with the effects of these behavioral frictions. The expressions for $\triangle W T P$, above, capture the potential difference between underlying and measured WTP under different frictional environments, as implied by the indirect utility model. Distinguishing between an environment where WTP is low and one where WTP is much higher but made artificially lower due to the presence of frictions leads to different policy implications.

\subsection{Estimating Changes in WTP Due to Frictions}

This conceptual framework can be translated for estimation, in order to infer the size of these frictions, and their impact on WTP and price elasticity. We exploit experimental variation in the reduction of consumer frictions associated with information provided in our letter intervention. Estimated changes in WTP reflect only the changes in WTP induced by our intervention, and can be thought of as a lower bound on the full influence of frictions on measured WTP.

As mentioned above, we interpret the implied value of the letters as changes in the WTP for insurance. ${ }^{42}$ To estimate the value of reducing these frictions, we re-write equation (3) in the reduced-form:

$$
u_{i}=x_{i}^{\prime} \beta+\gamma_{\text {Remind }} T_{i}^{\text {Remind }}+\gamma_{\text {Inform }} T_{i}^{\text {Inform }}+\left(\alpha+\tilde{\alpha} T_{i}^{\text {Inform }}\right) \tau_{i}+\varepsilon_{i}
$$

$T_{i}^{\text {Remind }}$ is an indicator for receiving reminder information (contained in treatment arms 2-5), and hence $\gamma_{\text {Remind }}$ is the value of getting that reminder, equivalent to a reduction in the cost of remembering to enroll, $c^{\text {Memory }}$. Similarly, $T_{i}^{\text {Inform }}$ is an indicator for receiving information in a letter with personalized subsidies (treatment arms 3-5), and hence $\gamma^{\text {Inform }}$ captures the additional value of getting that information, equivalent to the additional reduction in the costs of search, $c^{\text {Search }}$. $\alpha$ is the baseline price parameter of a potentially uninformed consumer, equal to $\alpha_{0}-\tilde{\alpha}$ (which is jointly estimated). $T_{i}^{\text {Inform }}$ also appears in consumers' response to subsidies, such that receipt of the subsidy-reporting

\footnotetext{
${ }^{41}$ Consider a simple example: if most consumers have no knowledge of the subsidies, the measured $\alpha$ will be close to 0 and the measured WTP will be relatively large. By informing all consumers of the subsidy level, even if take-up increases, the increase in $\alpha$ can cause the WTP to decrease.

${ }^{42}$ We also make the simplifying interpretation that the value of the letters are derived only from their impact on take-up. This is sensible given the present purpose of translating the value of letters to changes in WTP for insurance. In principle, the letters could have value beyond those measured by insurance demand (e.g. by improving plan choice, or creating trust in Covered California, etc.)-value we ignore for this exercise.
} 
letter offsets the effect of the search friction $\tilde{\alpha}$ contained in the underlying consumer price sensitivity, $\alpha$. Last, $x_{i}$ is a vector of household characteristics.

Under this parameterization, the expressions for changes on WTP in response to the interventions are:

$$
\Delta W T P(\text { Reminder })=\frac{\gamma_{\text {Remind }}}{\alpha}
$$

$$
\Delta W T P(\text { Subsidy Information })=\frac{\gamma_{\text {Inform }}-\frac{\widetilde{\alpha}}{\alpha+\widetilde{\alpha}} I_{i}}{\alpha} .
$$

Equations (5) and (6) provide a general framework for estimating the change in measured WTP from reducing frictions associated with enrollment. Note that $I_{i}$ is referenced in (6) but not in the estimating equation (4). ${ }^{43}$ We further address the implications of this in the next section with the empirical results. In practice, estimating the changes requires exogenous variation in the reduction of these frictions. Indeed, the parameters $\gamma_{j}$ are well-identified in the data using experimental variation in treatment assignment. However, estimating both terms of $\alpha$ is more complicated because APTC $\left(\tau_{i}\right)$ varies with age and income in a nonlinear way, and may be correlated with unobserved preferences for insurance, $\varepsilon$. And if lower income enrollees also value insurance less, and APTC declines with income, then estimate of $\alpha$ may be downwardly biased, upwardly biasing estimates of $\triangle W T P$.

To address this, we estimate the $\triangle W T P$ terms using two approaches. Our first approach is to estimate (4) directly and use the estimated parameters to get values for (5) and (6). Following Tebaldi (2017), we use household level variation in the APTC conditional on region, age, and income, to identify $\alpha . \alpha$ is identified in the data from how take-up varies with subsidy level, conditional on a rich set of control variables, including region, income, average age-based risk in the household (representing per-member expected healthcare costs), and the linear interaction of these income and risk measures. ${ }^{44}$

As reported below, the implied semi-elasticities from our estimates of $\alpha$ are consistent with Tebaldi (2017), and more importantly, consistent with market-wide elasticity estimates identified off of

\footnotetext{
${ }^{43}$ The joint term $I_{i}-I_{i}^{P}$ can be estimated as $x_{i}^{\prime} \beta+2\left(\gamma^{\text {Inform }}+\gamma^{\text {Remind }}\right)$. Unfortunately, plan utility without premiums $\left(I_{i}\right)$ cannot be determined in isolation from this specification. In our context, we estimate $\tilde{\alpha}$ to be approximately 0 so the impact of $I_{i}$ in (6) is negligible. In other situations, $I_{i}^{p}$ (and hence $I_{i}$ ) can be approximated using the estimated value of $\alpha$ and the set of premiums in the choice set.

${ }^{44}$ The remaining variation in subsidy level is largely driven by non-linearities in how family size impacts the federal poverty line, which is used in federal subsidy determination. Factors that typically drive demand for insurance, such as age, income, and health risk, are controlled for. Also, as noted in Ericson and Starc (2012), prices may be correlated with unobserved plan characteristics. Estimating sensitivity to subsidies in California's highly standardized marketplace avoids this additional source of endogeneity when estimating sensitivity to premiums.
} 
exogenous discontinuities in premium present in the pre-ACA Massachusetts health insurance market (Ericson and Starc, 2015), but smaller than recent estimates reported in Shepard (2017), Jaffe and Shepard (2017) and Finkelstein, Hendren, and Shepard (2017). Overall, the consistency implies that the bias in the first method is not large. ${ }^{45}$ Nevertheless, the largest semi-elasticity of the recent estimates, found in Finkelstein, Hendren and Shepard (2019), would imply the smallest change in WTP due to the letter interventions. ${ }^{46}$

Indeed, outside estimates of elasticities in exchange populations serve as useful benchmarks for our WTP estimation. As our second approach to calculating $\triangle W T P$, we calibrate our treatment effects reported earlier using elasticities reported in Finkelstein, Hendren and Shepard (2019). That is, we divide our estimated treatment effects (in percent) by their estimated semi-elasticity. While that study examines a different state, the discontinuities in marketplace subsidies provide a rigorous source of variation that does not exist in ACA markets. The semi-elasticities reported in Finkelstein, Hendren and Shepard (2019) are larger than those reported elsewhere. The resulting estimates of $\triangle W T P$ are smaller than those using our first strategy, and serve as the lower end of our preferred range of estimates.

\subsection{The Estimated Value of Letters and Changes in Measured WTP}

This section reports the empirical results of estimating the effects reducing frictions on measured WTP. In Table 8, we present the estimated coefficients from equation (4). In column (1), we estimate this model on the full sample. The largest effect comes from the reminder letters, where the positive coefficient implies increases in WTP due to receipt of reminder information. Estimates of $\gamma^{\text {Inform }}$ and $\tilde{\alpha}$ are statistically insignificant. In particular, the estimate for $\tilde{\alpha}$ is also economically insignificant,

\footnotetext{
${ }^{45}$ Ericson and Starc (2015) use discontinuities in pricing at age thresholds in the Massachusetts exchange, and report a semi-elasticity of -0.35 for a $\$ 100$ premium increase for the full sample, similar to our implied semielasticity of -0.4. Finkelstein, Hendren and Shepard (2019) use discontinuities in the subsidy design in Massachusetts to identify the effect of subsidies on take-up, and report a larger semi-elasticity of -0.25 for a $\$ 40$. Robustness in our estimates of $\alpha$ and WTP across various specifications of risk and income, and the similarity in our semi-elasticities to those estimated for Massachusetts, indicate that our model is not greatly impacted by this bias. ${ }^{46}$ Note that this approach is still subject to bias in our estimates of $\tilde{\alpha}$. While $T_{i}^{\text {Inform }}$ is randomly assigned, the interaction term $T_{i}^{\text {Inform }} \cdot \tau_{i}$, which captures the additional effect of $T_{i}^{\text {Inform }}$ for larger values of $\tau_{i}$, in equation (4) is not, and may be correlated with unobserved factors affecting demand. . To the extent our estimates $\tilde{\alpha}$ are biased, they are likely positively biased, resulting in underestimates of $\triangle W T P$ (Subsidy Information). Indeed, results in Section 5 suggest that larger values of $\tau_{i}$ (lower income and age) are likely to be correlated with higher frictions (and higher additional increases in indirect utility at higher levels of $\tau_{i}$ ), resulting in overestimates of $\tilde{\alpha}$, and underestimates of $\triangle W T P$ (Subsidy Information).
} 
suggesting that for the full sample, the subsidy-reporting information did not meaningfully alter consumer sensitivity to subsidies for take-up.

In column (2) (and all even columns), we make the simplifying assumption that $\tilde{\alpha}=0$. Doing so simplifies the estimation of $\triangle W T P$ since it no longer depends on $I_{i}$ as noted earlier. Because estimates of $\tilde{\alpha}$ are neither economically nor statistically different from 0 in any specification, we use even columns as our primary measures of $\triangle W T P$ in each subpopulation. At the bottom of the table, we report the estimates for the impact of the interventions on expected WTP for the consumer receiving the mean subsidy in the study sample. We find that the effect of the letters on the total expected WTP for insurance is $\$ 54$ per month for the full sample. $\triangle W T P$ (Reminder) is estimated to be $\$ 51$, suggesting that the primary increase in WTP is attributed to the reminder. The additional effect of informing consumers about their subsidies is to increase WTP by $\$ 2.61$, which while positive, is economically small and not statistically different from 0 .

As mentioned earlier, our estimates of $\triangle W T P$ may be positively biased given potential underestimation of $\alpha$. At the bottom of Table 8, we report estimated changes in WTP using our second approachcalibrating $\triangle W T P$ to semi-elasticities reported by Finkelstein, Hendren and Shepard (2019). Using this method, so we calculate $\triangle W T P$ (Reminder Letter) and $\triangle W T P$ (Subsidy Reporting Letters) to be $\$ 24.55$ and $\$ 0.39$, respectively, or approximately half the point estimates from our estimation method.

Similar patterns are observed for the full Open Enrollment sample, in columns (3) and (4). In columns (5) and (6) we report estimates for Open Enrollment Applicants below 180 percent of FPL, for whom we observed the largest effects on enrollment and positive risk selection. As expected, price sensitivity, $\alpha$, is much higher for the low income sample. For this sample, the dominant effect of the letters was also to raise WTP through the reminder. However, the subsidy information appears to have also increased WTP substantially. The effect of providing subsidy information for this low income population was to raise measured WTP for insurance by $\$ 17$. While the estimate for $\tilde{\alpha}$ in column (5) is larger in magnitude, it is still statistically and economically close to 0 .

For the County Referral population, the net effect of the letters raised WTP by (a statistically insignificant) \$37, with larger effects observed for the subsidy information and for lower income consumers. This larger point estimate for the subsidy information makes sense given the relatively low baseline awareness of program subsidies among consumers who are recently transitioning from Medicaid, particularly lower income consumers who are eligible for larger premium subsidies. However, 
the overall lower increase in WTP in the County Referral segment likely reflects the persistent lower levels of program awareness and hassle costs of enrollment, necessitating more intensive interventions to counter frictions in the market.

From a policy perspective, we can also interpret these results in subsidy equivalent units. That is, providing the letters has the same effect as increasing the monthly subsidy $\$ 25$ to $\$ 54$. Given the low cost of mailing these letters, this is a large benefit for a program aimed at increasing rates of coverage. To put these estimates in context, Finkelstein, Hendren and Shepard (2019) reports a median overall WTP for insurance among marketplace eligible consumers of around $\$ 100$, compared to an average monthly cost of coverage of $\$ 420$. Their estimated WTP distribution implies that half of eligible consumers would not take-up when offered a subsidy equal to 75 percent of premiums, and 20 percent would not take-up with a 90 percent subsidy. The marginal consumer offered a 90 percent subsidy has a WTP of $\$ 40$. Whether using the calibrated estimate of $\$ 25$ per month, or internally estimated $\$ 54$ per month, estimated increases in WTP associated with reduced frictions generated by a passive letter intervention represents a significant portion of the gap between measured WTP and net-of-subsidy costs. The low touch nature of the intervention also suggests that residual frictions may play a significant role in uninsurance. These include persistent lack of awareness of plan and subsidy benefits, as well as frictions associated with enrollment itself. Naturally, underlying WTP may also be subject to misperceptions about risks (Moore and Healy, 2008), misunderstanding about insurance design (Bhargava, Loewenstein and Sydnor, 2017), the availability of uncompensated care (Finkelstein, Hendren and Shepard, 2019), or distaste for public marketplace insurance (Lerman, Sadin and Trachtman, 2017).

\section{Conclusion}

This study documents the existence of economically significant behavioral frictions in health care enrollment. We find evidence that both inattention and information search costs reduce take-up rates in ACA markets, and that relatively inexpensive "low touch" informational interventions that lower inattention and informational search costs can improve take-up. Moreover, the marginal enrollee induced to enroll by the intervention is lower risk than inframarginal enrollees, contributing to lower average market risk, the majority of which are unobserved, or by statute, cannot be priced in by plans.

Notably, positive selection effects were observed only in the Open Enrollment Applicant sample, highlighting the importance of baseline informational environment and risk selection when projecting 
potential selection effects of an intervention. Our evidence suggests that the marginal respondent to letters that reduced search costs and behavioral frictions in the relatively better-informed Open Enrollment sample was healthier, conditional on age. This pattern is consistent with a model of adverse selection where sicker consumers have already incurred both behavioral and financial cost to enroll without any intervention, and where lowering frictions induced healthier consumers into the market. County Referral households were likely less familiar with plan options and available subsidies. As a result, they had lower levels of baseline take-up, and marginal respondents from this group to letters reducing frictions comprised both low and high risk consumers.

Overall, the letters raised overall enrollment in the study population by $1.3 p p$, or 16 percent. Using a structural demand model to translate these effect sizes, we find that the letters raised measured WTP for insurance by the equivalent of $\$ 25$ to $\$ 54$ in the monthly subsidy for this sample. Given recent estimates of willingness-to-pay for marketplace insurance on the order of $\$ 100$, our estimates suggest that measured willingness-to-pay for insurance is substantially impacted by frictions, and that revealed preference-based approaches will underestimate the standalone value of insurance in the presence of frictions in enrollment. Recent studies also conclude that increasing subsidies may play a limited role at raising enrollment. While our study is consistent with low estimates of WTP among marginal enrollees, our findings also suggest that pairing subsidies with efforts to inform consumers and to simplify enrollment may increase enrollment substantially more than through subsidies alone.

Moreover, the implied increase in willingness-to-pay in response to a low-touch intervention highlights the potential for further reducing behavioral frictions in order to increase enrollment and improve market risk. More intensive outreach and education with personalized information, particularly among more highly-subsidized consumers, could raise enrollment. Stronger evidence from our study supports simplifying enrollment processes. This could involve reminder emails with easy links to enrollment, or reminder letters with prepaid mail-in enrollment forms. Default enrollment, or auto-enrollment, would further reduce the hassle cost of enrollment. Indeed, in recent research, Shepard (2019) finds positive enrollment and selection effects of easing enrollment through auto-enrollment in Massachusetts.

Finally, heterogeneity in treatment effects between Open Enrollment and County Referral samples reported throughout the study highlights the need for policymakers to consider the population of interest when extrapolating these results beyond this study. Our results suggest that the enrollment and positive risk selection effects were larger in the Open Enrollment sample, where prevailing level of consumer awareness could have induced adverse selection, allowing for positive selection in response 
to the intervention. In contrast, we find null effects on risk for the relatively less-informed Medicaidtransitioning population. Despite not generating positive risk selection, the null effects of the letters for the County Referral segment allay concerns that easing enrollment among special enrollment populations may raise risk and destabilize premiums (AHIP, 2016; Federal Register, 2017a, 2017b). Our results also suggest that interventions beyond marginal reductions in frictions may generate larger positive selection effects, as marginal respondents become healthier.

Note that the results of this study occurred from a relatively low-cost intervention in a marketplace environment in which paid marketing to promote enrollment was relatively widespread. Applied to other marketplaces that begin with a lower baseline level of outreach, a similar intervention might result in greater impacts (to the extent that personalized letters might act as a primary reminder of deadlines or source of information about plans and benefits), or lesser impacts than those observed in California, if treatment effects described in this study depend on the other marketing and outreach already in place.

Our findings are particularly relevant in light of recent regulatory actions to defund ACA marketing, such as a 90 percent reduction in advertising, and a 40 percent cut in navigator programs, in the federallyfacilitated marketplaces (Goodnough and Pear, 2017; Lodes, 2017). More generally, the design of the ACA follows recent movements in publicly-financed insurance, such as Medicare Advantage and Part D, in which choice is devolved to individuals, fostering competition among private insurers and providers. Success of this model depends on how well individuals make health insurance decisions, raising the importance of developing policies that improve consumer decision-making in health care. 


\section{References}

Abaluck, Jason, and Jonathan Gruber. 2011. "Choice Inconsistencies among the Elderly: Evidence from Plan Choice in the Medicare Part D Program." American Economic Review 101(4): 1180-210.

Bertrand, Marianne, Sendhil Mullainathan, and Eldar Shafir. 2006. "Behavioral economics and marketing in aid of decision making among the poor." Journal of Public Policy and Marketing, 25(1): 8-23.

Bhargava, Saurabh, and Dayanand Manoli. 2015. "Psychological Frictions and the Incomplete Take-Up of Social Benefits: Evidence from an IRS Field Experiment." American Economic Review, 105(11): 3489-529.

Bhargava, Saurabh, George Loewenstein, and Justin Sydnor. 2017. "Choose to Lose: Health Plan Choices from a Menu with Dominated Options." Quarterly Journal of Economics 132(3): 1319-72.

Blumberg, Linda J., and Matthew Buettgens. 2013. Why the ACA's Limits on Age-Rating Will Not Cause "Rate Shock": Distributional Implications of Limited Age Bands in Nongroup Health Insurance. Urban Institute, and Robert Wood Johnson Foundation.

Chandra, Amitabh, Jonathan Gruber, and Robin McKnight. 2011. "The Importance of the Individual Mandate: Evidence from Massachusetts." New England Journal of Medicine 364(4): 293-95.

Chetty, Raj, John N. Friedman, and Emmanuel Saez. 2013. "Using Differences in Knowledge Across Neighborhoods to Uncover the Impacts of the EITC on Earnings." American Economic Review, 103(7): 2683-721.

Chetty, Raj, Adam Looney, and Kory Kroft. 2009. "Salience and Taxation: Theory and Evidence." American Economic Review 99(4), 1145-77.

Chetty, Raj, and Emmanuel Saez. 2013. "Teaching the Tax Code: Earnings Responses to an Experiment with EITC Recipients." American Economic Journal: Applied Economics 5(1): 1-31.

CMS. 2018. Early 2018 Effectuated Enrollment Snapshot. Center for Medicare and Medicaid Services.

Currie, Janet. 2006. "The Take-up of Social Benefits." In Public Policy and the Income Distribution, edited by Alan J. Auerbach, David Card, and John M. Quigley, 80-148. New York: Russell Sage Foundation.

Dodds, William B., Kent B. Monroe, and Dhruv Grewel. 1991. "Effects of Price, Brand, and Store Information on Buyers' Product Evaluations." Journal of Marketing Research 28(3) 307-19.

Ericson, Keith M. 2011. "Forgetting We Forget: Overconfidence and Memory." Journal of the European Economic Association 9(1): 43-60.

Ericson, Keith M., and Amanda Starc. 2012. "Heuristics and Heterogeneity in Health Insurance Exchanges: Evidence from the Massachusetts Connector." American Economic Review 102(3): 493-7.

Ericson, Keith M. 2014. "Consumer Inertia and Firm Pricing in the Medicare Part D Prescription Drug Insurance Exchange." American Economic Journal: Economic Policy 6(1): 38-64.

Ericson, Keith M., and Amanda Starc. 2015. "Pricing Regulation and Imperfect Competition on the Massachusetts Health Insurance Exchange." Review of Economics and Statistics 97(3): 667-82.

Ericson, Keith M. 2016. "When Consumers Do Not Make an Active Decision: Dynamic Default Rules and their Equilibrium Effects." Unpublished.

Ericson, Keith M., and Amanda Starc. 2016. "How product standardization affects choice: Evidence from the Massachusetts Health Insurance Exchange." Journal of Health Economics 50:71-85.

Ericson, Keith M., 2017. "On the Interaction of Memory and Procrastination: Implications for Reminders, Deadlines, and Empirical Estimation." Journal of the European Economic Association 15(3): 692-719.

Ericson, Keith M., and Justin Sydnor. 2017. "The Questionable Value of Having a Choice of Levels of Health Insurance Coverage." Journal of Economic Perspectives 31(4): 51-72.

Ericson, Keith M., Jon Kingsdale, Tim Layton, and Adam Sacarny. 2017. "Nudging Leads Consumers In Colorado To Shop But Not Switch ACA Marketplace Plans." Health Affairs 36(2): 311-9. 
Federal Register. 2017. Proposed Rules: Department of Health and Human Services, 45 CFR Parts 147, 155, and 156. Federal Register 82(32): 10980-98.

Federal Register. 2017. Rules and Regulations: Department of Health and Human Services, 45 CFR Parts 147, 155, and 156. Federal Register 82(73): 18346-82.

Finkelstein, Amy, Nathaniel Hendren, and Mark Shepard. 2019. "Subsidizing Health Insurance for LowIncome Adults: Evidence from Massachusetts." American Economic Review 109(4): 1530-67.

Eyles, Matthew, and Justine Handelman. 2016. Appropriate Use of Special Enrollment Periods Is Key to Exchange Stability, Affordability for Consumers. America's Health Insurance Plans, and BlueCross BlueShield Association.

Geruso, Michael, Timothy J. Layton, Grace McCormack, and Mark Shepard. 2019. "The Two Margin Problem in Insurance Markets." Unpublished.

Geruso, Michael, and Timothy J. Layton. 2017. "Selection in Health Insurance Markets and Its Policy Remedies." Journal of Economic Perspectives 31(4): 23-50.

Gonzales, Shelby. 2017. Trump Administration Slashing Funding for Marketplace Enrollment Assistance and Outreach. Center on Budget and Policy Priorities.

Goodnough, Abby, and Robert Pear. 2017. Trump Administration Sharply Cuts Spending on Health Law Enrollment. New York Times.

Greenberg. 2017. Wave 2: A Quantitative Study on Current Attitudes of Uninsured and Select Insured Californians Toward Health Insurance Coverage. Greenberg Strategy.

Hackmann, Martin B., Jonathan T. Kolstad, and Amanda E. Kowalski. 2015. "Adverse Selection and an Individual Mandate: When Theory Meets Practice." American Economic Review 105(3): 1030-66.

Handel, Benjamin R. 2013. "Adverse Selection and Inertia in Health Insurance Markets: When Nudging Hurts." American Economic Review 103(7): 2643-82.

Handel, Benjamin R., Igal Hendel, and Michael D. Whinston. 2015. "Equilibria in Health Exchanges: Adverse Selection vs. Reclassification Risk." Econometrica 83(4): 1261-1313.

Handel, Benjamin R., and Jonathan T. Kolstad. 2015. "Health Insurance for 'Humans': Information Frictions, Plan Choice, and Consumer Welfare." American Economic Review 105(8): 2449-500.

Handel, Benjamin R., Jonathan T. Kolstad, and Johannes Spinnewijn. 2019. "Information Frictions and Adverse Selection: Policy Interventions in Health Insurance Markets." Review of Economics and Statistics 101(2): 326-40.

Heffetz, Ori, Ted O'Donoghue, and Henry S. Schneider. 2016. "Forgetting and Heterogeneity in Task Delay: Evidence from New York City Parking-Ticket Recipients." NBER Working Paper No. 23012.

Hinde, Jesse M. 2017. "Incentive(less)? The Effectiveness of Tax Credits and Cost-Sharing Subsidies in the Affordable Care Act." American Journal of Health Economics 3(3): 346-69.

Jaffe, Sonia P., and Mark Shepard. 2018. "Price-Linked Subsidies and Imperfect Competition in Health Insurance." Unpublished.

Karlan, Dean, Margaret McConnell, Sendhil Mullainathan, and Jonathan Zinman. 2016. "Getting to the Top of Mind: How Reminders Increase Saving." Management Science 62(12): 3393-411.

Ketcham, Jonathan, Claudio Lucarelli, Eugenio Miravete and M. Christopher Roebuck. 2012. "Sinking, Swimming, or Learning to Swim in Medicare Part D." American Economic Review 102(6): 2639-73.

Kling, Jeffrey R., Sendhil Mullainathan, Eldar Shafir, Lee C. Vermeulen, and Marian V. Wrobel. 2012. "Comparison Friction: Experimental Evidence from Medicare Drug Plans." Quarterly Journal of Economics 127(1): 199-235.

Kőszegi, Botond, and Matthew Rabin. 2006. "A Model of Reference-Dependent Preferences." Quarterly Journal of Economics 121(4): 1133-65.

Lee, Peter V., Vishaal Pegany, James Scullary, and Colleen Stevens. 2017. Marketing Matters: Lessons from California to Promote Stability and Lower Costs in National and State Individual Insurance Markets. Covered California. 
Lerman, Amy, Meredith Sadin and Samuel Trachtman. 2017. "Policy Uptake as Political Behavior: Evidence from the Affordable Care Act" American Political Science Review 111, 4, 755-770

Liebman, Jeffrey B., and Erzo F. P. Luttmer. 2015. "Would People Behave Differently If They Better Understood Social Security? Evidence from a Field Experiment." American Economic Journal: Economic Policy 7(1): 275-99.

Lodes, Lori. 2017. I ran ACA outreach under Obama. Trump's funding cuts could ruin the health care law. Vox.

Madrian, Brigitte C., and Dennis F. Shea. 2001. "The Power of Suggestion: Inertia in 401(k) Participation and Savings Behavior." Quarterly Journal of Economics 116(4):1149-87.

Mani, Anandi, Sendhil Mullainathan, Eldar Shafir, and Jiaying Zhao. 2013. "Poverty Impedes Cognitive Function." Science 341(6149): 976-80.

Milkman, Katherine L., John Beshears, James J. Choi, David Laibson, and Brigitte C. Madrian. 2011. "Using implementation intentions prompts to enhance influenza vaccination rates." PNAS 108(26): 10415-20.

Moore, Don A., and Paul J. Healy. 2008. "The Trouble with Overconfidence." Psychological Review 115(2): 502-17.

Mullainathan, Sendhil, and Eldar Shafir. 2014. Scarcity: The New Science of Having Less and How It Defines Our Lives. New York: Picador.

Polyakova, Maria. 2016. "Regulation of Insurance with Adverse Selection and Switching Costs: Evidence from Medicare Part D." American Economic Journal: Applied Economics 8(3): 165-95.

Ruggles, Steven, Katie Genadek, Ronald Goeken, Josiah Grover, and Matthew Sobek. IPUMS-USA, University of Minnesota, www.ipums.org, 2017.

Seervai, Shanoor. 2017. Cuts to the ACA's Outreach Budget Will Make It Harder for People to Enroll. The Commonwealth Fund.

Shepard, Mark. 2019. "Does Automatic Matter for Health Insurance Markets? Evidence from Massachusetts." Unpublished.

Smeeding, Timothy M., Katherin Ross Phillips, and Michael A. O'Connor. 2011. "The EITC: Expectation, Knowledge, Use, and Economic and Social Mobility." National Tax Journal 53(4): 1187-1210.

Tebaldi, Pietro. 2017. "Estimating Equilibrium in Health Insurance Exchanges: Price Competition and Subsidy Design under the ACA." Unpublished. 
Figure 1. Take-up Rates, by Treatment Status

(a) Open Enrollment Sample

(b) County Referral Sample
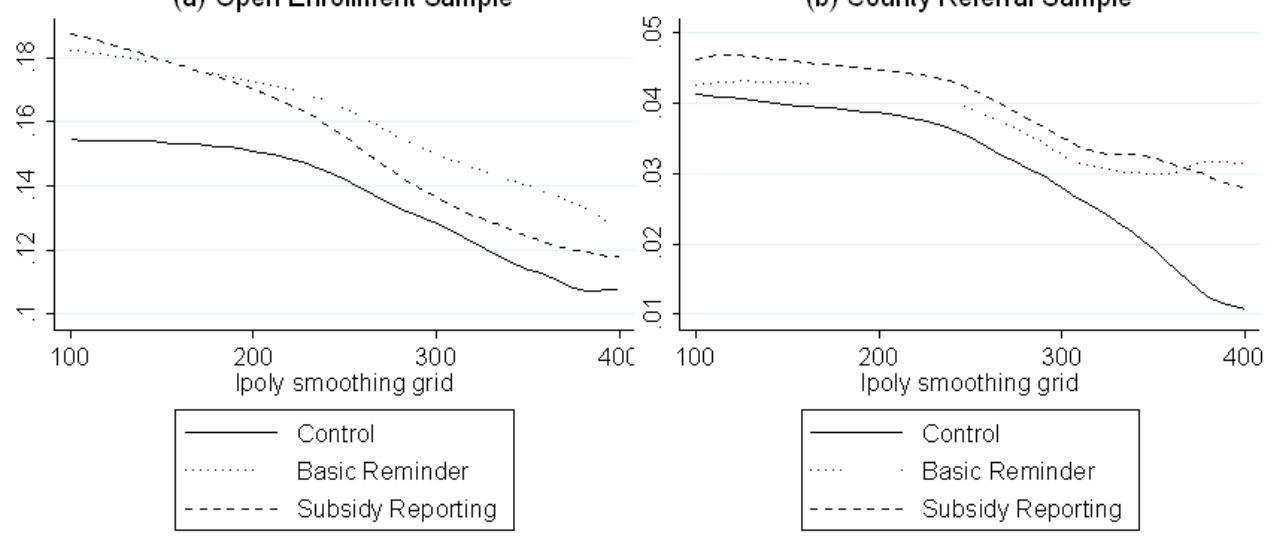

Notes: Figure 1 plots kernel regressions of 2016 take-up of Covered California insurance against household income (percent of FPL), by treatment assignment. Figure (a) restricts the sample to the Open Enrollment sample, while the sample in Figure (b) is restricted to the County Referral sample.

\section{Figure 2. Average Risk by Treatment, Among Enrolled}
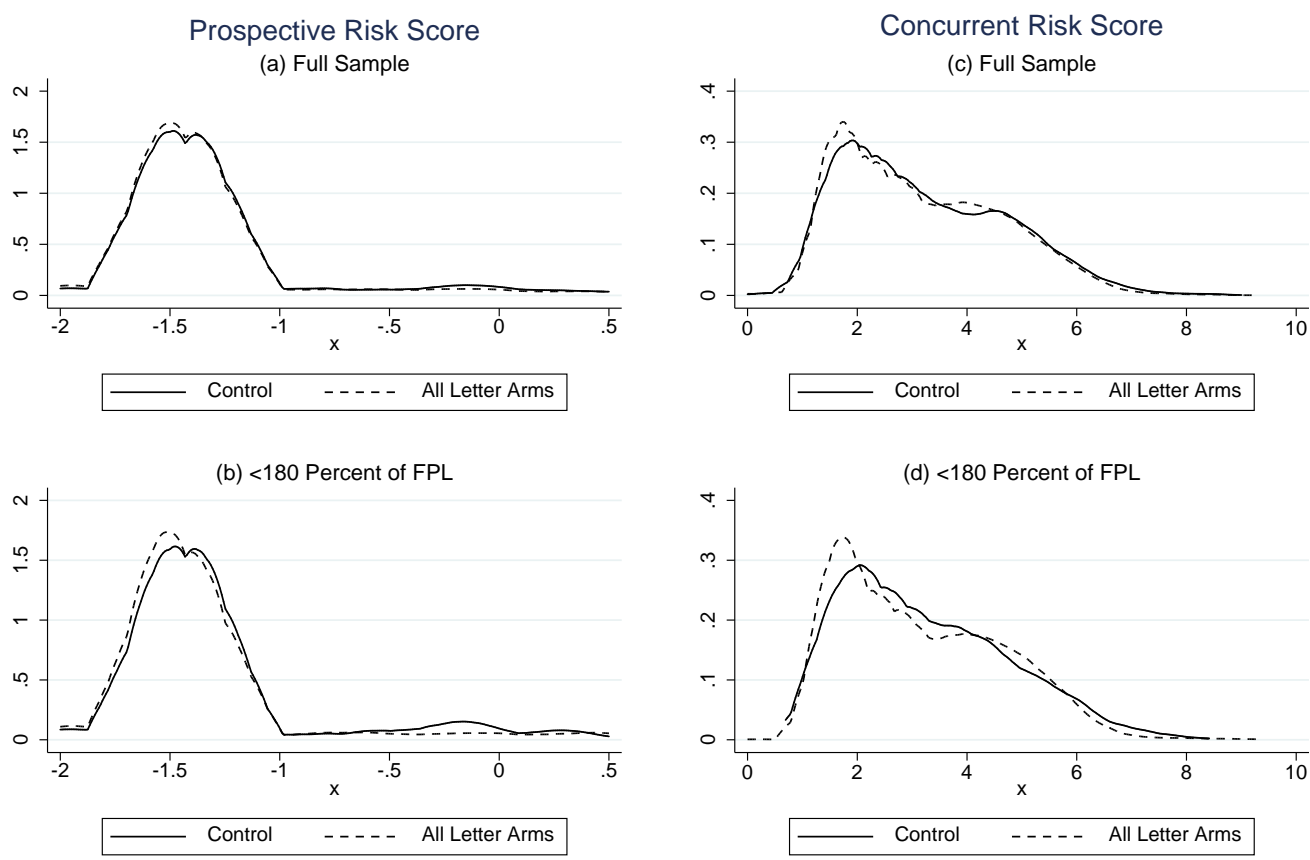

Notes: Figure 2 plots the kernel densities of the In(risk score) for the full study sample, separately for the control group and the combined intervention arms. Figures (a) and (b) report the CDPS prospective risk scores based on diagnoses from 2015 hospital and emergency department encounters (truncated at 0.5). (c) and (d) use concurrent risk scores based on full claims realized during the 2016 plan year following the intervention. Appendix Figures 1-2 displays kernel densities, separately for the open enrollment and country referral samples. Appendix Figure 3 compares the distribution of risk of the basic reminder arm to the subsidy-reporting arms. 
Table 1. Demographics of Each Population

\begin{tabular}{lccc}
\hline \hline & Study Sample & Covered CA 2015 & Uninsured 2015 \\
\hline & $(1)$ & $(2)$ & $(3)$ \\
\cline { 2 - 4 } HH Age (mean) & 36.96 & 41.74 & 35.71 \\
SD of HH Age & 14.27 & 13.25 & 12.41 \\
FPL (FPL<400) & 215.23 & 210.49 & 211.52 \\
SD of FPL & 65.29 & 66.44 & 78.92 \\
FPL > 400 (share) & 0.21 & 0.10 & 0.19 \\
\hline Male (share) & 0.47 & 0.48 & 0.56 \\
Female (share) & 0.53 & 0.52 & 0.44 \\
White (share) & 0.25 & 0.32 & 0.23 \\
Latino (share) & 0.43 & 0.21 & 0.35 \\
Asian (share) & 0.13 & 0.17 & 0.10 \\
Black (share) & 0.04 & 0.02 & 0.04 \\
\hline \hline
\end{tabular}

Table 1 reports household-level income and demographic characteristics of the study sample, the 2015 California subsidized marketplace (Covered California), and the 2015 uninsured population in California.

Table 2. Summary Statistics, by Arm

\begin{tabular}{|c|c|c|c|c|c|c|c|c|}
\hline & \multicolumn{5}{|c|}{ Treatment Arm } & \multirow[b]{2}{*}{ Total } & \multirow[b]{2}{*}{$\begin{array}{l}\text { P-value } \\
\text { All arms }\end{array}$} & \multirow[b]{2}{*}{$\begin{array}{c}\text { P-value } \\
\text { Arm } 1\end{array}$} \\
\hline & Control & $\begin{array}{c}\text { Reminder } \\
\text { Only }\end{array}$ & Subsidy & $\begin{array}{l}\text { Subsidy+ } \\
\text { Price }\end{array}$ & $\begin{array}{c}\text { Subsidy+ } \\
\text { Price+Qual }\end{array}$ & & & \\
\hline & (1) & $(2)$ & (3) & (4) & (5) & (6) & (7) & $(8)$ \\
\hline Letter FPL & 212.40 & 211.98 & 212.45 & 211.89 & 212.52 & 212.25 & 0.86 & 0.74 \\
\hline Actual FPL & 207.04 & 206.71 & 206.49 & 206.39 & 206.98 & 206.72 & 0.89 & 0.51 \\
\hline White & 0.259 & 0.258 & 0.261 & 0.260 & 0.254 & 0.258 & 0.62 & 0.77 \\
\hline Latino & 0.426 & 0.427 & 0.432 & 0.425 & 0.430 & 0.428 & 0.62 & 0.58 \\
\hline Asian & 0.122 & 0.124 & 0.121 & 0.125 & 0.123 & 0.123 & 0.79 & 0.64 \\
\hline Black & 0.046 & 0.047 & 0.042 & 0.046 & 0.046 & 0.045 & 0.33 & 0.52 \\
\hline Spanish lang. & 0.167 & 0.169 & 0.167 & 0.167 & 0.170 & 0.168 & 0.89 & 0.60 \\
\hline HH Size & 1.396 & 1.391 & 1.396 & 1.395 & 1.393 & 1.394 & 0.96 & 0.76 \\
\hline Married & 0.488 & 0.480 & 0.480 & 0.480 & 0.481 & 0.482 & 0.52 & 0.08 \\
\hline HH Age (mean) & 37.69 & 37.90 & 37.59 & 37.60 & 37.46 & 37.65 & 0.06 & 0.65 \\
\hline CDPS Risk Score & 0.412 & 0.414 & 0.417 & 0.412 & 0.405 & 0.412 & 0.85 & 0.96 \\
\hline HH Risk Ratio & 1.99 & 2.01 & 1.99 & 1.99 & 1.98 & 1.99 & 0.57 & 0.97 \\
\hline Sample Size & 17378 & 17431 & 17521 & 17509 & 17555 & 87394 & & \\
\hline
\end{tabular}

Table 2 reports income and demographic characteristics reported in the administrative data, for the final study sample, by treatment arm. Column (7) reports the $p$-value on the null that the mean across all arms are equal. Column (8) reports the $p$-value on the null that the control group mean is equal to the rest of the sample. 
Table 3. Average Treatment Effects on Take-up

\begin{tabular}{|c|c|c|c|c|c|c|c|c|}
\hline \multicolumn{9}{|c|}{ Panel A: OLS } \\
\hline \multirow[t]{2}{*}{ Funnel Sample } & \multicolumn{2}{|c|}{ All } & \multicolumn{3}{|c|}{ Open Enrollment } & \multicolumn{3}{|c|}{ County Referral } \\
\hline & $(1)$ & $(2)$ & (3) & (4) & $(5)$ & $(6)$ & (7) & (8) \\
\hline Arm2345: All Letters & $\begin{array}{c}0.013^{* * *} \\
(0.002)\end{array}$ & $\begin{array}{c}0.011^{* * *} \\
(0.002)\end{array}$ & $\begin{array}{c}0.016 * * * \\
(0.004)\end{array}$ & & & $\begin{array}{c}0.006 * * * \\
(0.002)\end{array}$ & & \\
\hline Arm2: Reminder & & & & $\begin{array}{c}0.017^{* * *} \\
(0.005)\end{array}$ & $\begin{array}{c}0.017^{* * *} \\
(0.005)\end{array}$ & & $\begin{array}{c}0.004 \\
(0.003)\end{array}$ & $\begin{array}{c}0.004 \\
(0.003)\end{array}$ \\
\hline Arm345: Subsidy Reporting & & & & $\begin{array}{c}0.016 * * * \\
(0.004)\end{array}$ & & & $\begin{array}{c}0.007^{* * *} \\
(0.002)\end{array}$ & \\
\hline Arm3: Subsidy-Penalty & & & & & $\begin{array}{c}0.019 * * * \\
(0.005)\end{array}$ & & & $\begin{array}{c}0.007 * * \\
(0.003)\end{array}$ \\
\hline Arm4: Price Compare & & & & & $\begin{array}{c}0.012^{* *} \\
(0.005)\end{array}$ & & & $\begin{array}{c}0.006 * * \\
(0.003)\end{array}$ \\
\hline Arm5: Price-Quality Compare & & & & & $\begin{array}{c}0.015^{* * *} \\
(0.005)\end{array}$ & & & $\begin{array}{c}0.006 * * \\
(0.003)\end{array}$ \\
\hline Control Group Take-up Rate & 0.081 & 0.081 & 0.127 & 0.127 & 0.127 & 0.036 & 0.036 & 0.036 \\
\hline Controls and Region FE & $\mathrm{N}$ & $\mathrm{Y}$ & Y & $\mathrm{Y}$ & Y & $\mathrm{Y}$ & $\mathrm{Y}$ & $\mathrm{Y}$ \\
\hline Observations & 87,394 & 87,394 & 44,248 & 44,248 & 44,248 & 43,146 & 43,146 & 43,146 \\
\hline R-squared & 0.000 & 0.055 & 0.035 & 0.035 & 0.035 & 0.018 & 0.018 & 0.018 \\
\hline \multicolumn{9}{|c|}{ Panel B: Logit } \\
\hline Entry Sample & A & II & Ope & en Enrollm & ent & & unty Refer & \\
\hline & $(1)$ & $(2)$ & (3) & (4) & $(5)$ & $(6)$ & (7) & (8) \\
\hline Arm2345: All Letters & $\begin{array}{c}0.158 * * * \\
(0.031)\end{array}$ & $\begin{array}{c}0.147^{* * *} \\
(0.032)\end{array}$ & $\begin{array}{c}0.142 * * * \\
(0.036)\end{array}$ & & & $\begin{array}{c}0.160 * * \\
(0.064)\end{array}$ & & \\
\hline Arm2: Reminder & & & & $\begin{array}{c}0.151^{* * *} \\
(0.045)\end{array}$ & $\begin{array}{c}0.151^{* * *} \\
(0.045)\end{array}$ & & $\begin{array}{c}0.104 \\
(0.081)\end{array}$ & $\begin{array}{c}0.104 \\
(0.081)\end{array}$ \\
\hline Arm345: Subsidy Reporting & & & & $\begin{array}{c}0.138 * * * \\
(0.037)\end{array}$ & & & $\begin{array}{c}0.179 * * * \\
(0.066)\end{array}$ & \\
\hline Arm3: Subsidy-Penalty & & & & & $\begin{array}{c}0.168 * * * \\
(0.045)\end{array}$ & & & $\begin{array}{c}0.197 * * \\
(0.079)\end{array}$ \\
\hline Arm4: Price Compare & & & & & $\begin{array}{c}0.110 * * \\
(0.045)\end{array}$ & & & $\begin{array}{c}0.163 * * \\
(0.080)\end{array}$ \\
\hline Arm5: Price-Quality Compare & & & & & $\begin{array}{c}0.136 * * * \\
(0.045)\end{array}$ & & & $\begin{array}{c}0.176 * * \\
(0.080)\end{array}$ \\
\hline Controls and Region FE & $\mathrm{N}$ & $\mathrm{Y}$ & $\mathrm{Y}$ & $\mathrm{Y}$ & $\mathrm{Y}$ & $\mathrm{Y}$ & $\mathrm{Y}$ & $\mathrm{Y}$ \\
\hline Observations & 87,394 & 87,394 & 44,248 & 44,248 & 44,248 & 43,146 & 43,146 & 43,146 \\
\hline R-squared & 0.000 & 0.055 & 0.035 & 0.035 & 0.035 & 0.018 & 0.018 & 0.018 \\
\hline
\end{tabular}

Table 3 reports OLS treatment effects of letter interventions on take-up of 2016 open enrollment coverage.

Columns (1)-(2) are estimated on the full study sample. Columns (3)-(6) and (6)-(8) restrict the sample to the Open Enrollment and County Referral samples, respectively. In all columns except for column (1), the regression includes household level controls, including family size, number of kids, age, race, language preferences, marital status, Covered California's age-based community-rating premium ratio, and household income (as percent of the FPL). Panel B reports analogous regression results of a logit specification. Robust standard errors in parentheses. ${ }^{* * *} \mathrm{p}<0.01,{ }^{* *} \mathrm{p}<0.05,{ }^{*} \mathrm{p}<0.1$ 
Table 4. Treatment Effects on Take-up, by Household Income

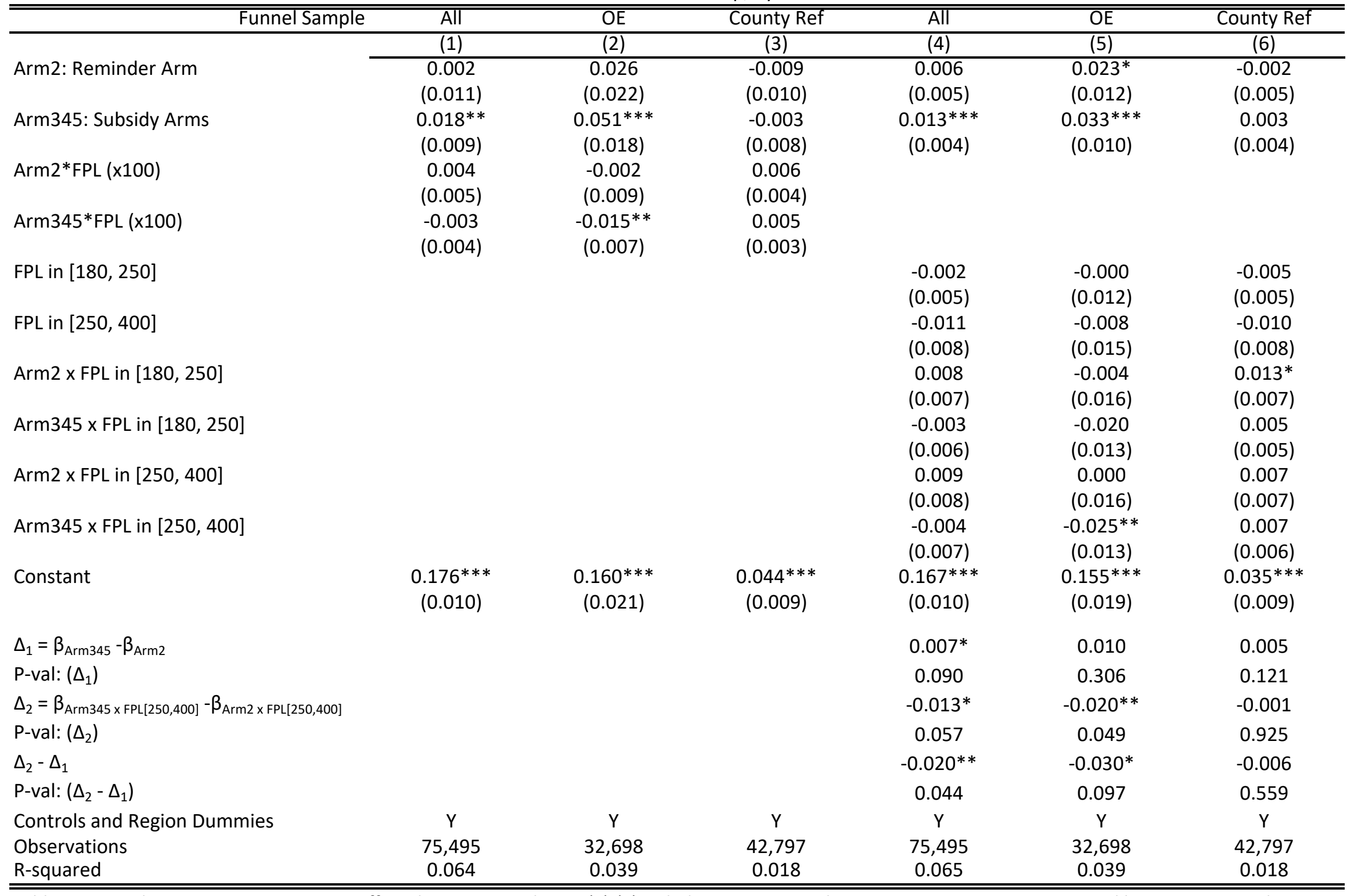

Table 4 reports heterogeneous treatment effects by income. Columns (1)-(3) include an interaction between treatment assignment and linear income. Columns (4)-(6) include a non-parametric income specification. $\Delta_{1}$ reports the additional treatment effect of the Subsidy Reporting arms over the reminder-only letter for the $<180 \mathrm{FPL}$ segment. $\Delta_{2}$ reports the same effect for the 250-400 FPL segment. $\left(\Delta_{2}-\Delta_{1}\right)$ reports the difference in the relative effects. All regressions control for household level characteristics listed in Table 3. Robust standard errors in parentheses. ${ }^{* * *} p<0.01,{ }^{* *} p<0.05,{ }^{*} p<0.1$ 
Table 5. Heterogeneous Treatment Effects, by Baseline Risk (Controling for Age Factors and Regions)

\begin{tabular}{|c|c|c|c|c|c|c|c|c|c|c|c|c|}
\hline \multirow{3}{*}{$\begin{array}{c}\text { Funnel Sample } \\
\text { Income Sample }\end{array}$} & \multicolumn{2}{|c|}{ All } & \multicolumn{5}{|c|}{ Open Enrollment } & \multicolumn{5}{|c|}{ County Referral } \\
\hline & \multicolumn{2}{|c|}{ All } & All & All & $\leq 180 \mathrm{FPL}$ & $180-250$ & $>250 \mathrm{FPL}$ & All & All & $\leq 180 \mathrm{FPL}$ & $180-250$ & $>250 \mathrm{FPL}$ \\
\hline & $(1)$ & $(2)$ & (3) & (4) & (5) & (6) & (7) & (8) & (9) & $(10)$ & (11) & $(12)$ \\
\hline \multirow[t]{2}{*}{ Arm2345: All Letters } & 0.008 & & 0.002 & & & & & 0.010 & & & & \\
\hline & $(0.008)$ & & $(0.015)$ & & & & & $(0.007)$ & & & & \\
\hline \multirow[t]{2}{*}{ Arm2: Reminder } & & 0.013 & & 0.008 & 0.025 & 0.030 & -0.003 & & $0.017^{*}$ & $0.030 * *$ & 0.010 & -0.006 \\
\hline & & $(0.010)$ & & (0.019) & $(0.044)$ & $(0.040)$ & $(0.025)$ & & $(0.009)$ & $(0.014)$ & $(0.017)$ & $(0.015)$ \\
\hline \multirow[t]{2}{*}{ Arm345: Subsidy Arms } & & 0.007 & & 0.000 & 0.018 & -0.006 & -0.003 & & 0.008 & $0.021 *$ & 0.001 & -0.011 \\
\hline & & $(0.008)$ & & $(0.015)$ & $(0.035)$ & $(0.033)$ & $(0.020)$ & & $(0.007)$ & $(0.011)$ & $(0.014)$ & $(0.012)$ \\
\hline \multirow[t]{2}{*}{ Age Rating } & $0.017 * * *$ & $0.017 * * *$ & $0.012 * *$ & $0.012 * *$ & $0.041^{* * *}$ & $0.032 * *$ & 0.000 & $0.019 * * *$ & $0.019 * * *$ & $0.021 * * *$ & $0.022 * * *$ & 0.006 \\
\hline & $(0.003)$ & $(0.003)$ & $(0.006)$ & $(0.006)$ & $(0.015)$ & $(0.014)$ & $(0.007)$ & $(0.003)$ & $(0.003)$ & $(0.005)$ & $(0.006)$ & $(0.005)$ \\
\hline \multirow[t]{2}{*}{ In(CDPS Score) } & $-0.005^{*}$ & $-0.005^{*}$ & 0.003 & 0.003 & -0.003 & -0.004 & 0.008 & $-0.005^{* *}$ & $-0.005 * *$ & $-0.008 * *$ & -0.004 & -0.000 \\
\hline & $(0.003)$ & $(0.003)$ & $(0.006)$ & $(0.006)$ & $(0.013)$ & $(0.012)$ & $(0.009)$ & $(0.003)$ & $(0.003)$ & $(0.004)$ & $(0.005)$ & $(0.006)$ \\
\hline \multirow[t]{2}{*}{ Arm2345 x In(CDPS Risk) } & $-0.009 * *$ & & $-0.021 * * *$ & & & & & 0.001 & & & & \\
\hline & $(0.003)$ & & $(0.007)$ & & & & & $(0.003)$ & & & & \\
\hline \multirow[t]{2}{*}{ Arm2 x In(CDPS Risk) } & & $-0.008 *$ & & $-0.018 * *$ & -0.027 & -0.017 & -0.012 & & 0.003 & $0.010^{*}$ & -0.001 & -0.008 \\
\hline & & $(0.004)$ & & $(0.009)$ & $(0.020)$ & $(0.017)$ & $(0.013)$ & & $(0.004)$ & $(0.006)$ & $(0.007)$ & $(0.007)$ \\
\hline \multirow[t]{2}{*}{ Arm345 x In(CDPS Risk) } & & $-0.009 * *$ & & $-0.021 * * *$ & $-0.033 * *$ & -0.021 & -0.014 & & 0.000 & 0.004 & -0.002 & -0.004 \\
\hline & & $(0.004)$ & & $(0.007)$ & $(0.015)$ & $(0.014)$ & $(0.010)$ & & $(0.003)$ & $(0.005)$ & $(0.006)$ & $(0.006)$ \\
\hline \multirow[t]{2}{*}{ Arm2345 x Age Rating } & -0.005 & & -0.008 & & & & & -0.002 & & & & \\
\hline & $(0.004)$ & & $(0.006)$ & & & & & $(0.004)$ & & & & \\
\hline \multirow[t]{2}{*}{ Arm2 x Age Rating } & & -0.007 & & -0.008 & -0.024 & -0.022 & 0.002 & & -0.007 & $-0.013^{* *}$ & -0.001 & 0.001 \\
\hline & & $(0.005)$ & & $(0.008)$ & $(0.021)$ & $(0.019)$ & $(0.010)$ & & $(0.004)$ & $(0.006)$ & $(0.009)$ & $(0.008)$ \\
\hline \multirow[t]{2}{*}{ Arm345 x Age Rating } & & -0.004 & & -0.007 & -0.019 & -0.006 & -0.003 & & -0.001 & -0.008 & 0.004 & $0.011^{*}$ \\
\hline & & $(0.004)$ & & $(0.007)$ & $(0.017)$ & $(0.016)$ & $(0.008)$ & & $(0.004)$ & $(0.006)$ & $(0.007)$ & $(0.006)$ \\
\hline \multirow[t]{2}{*}{ Constant } & $0.053 * * *$ & $0.053^{* * *}$ & $0.117^{* * *}$ & $0.116 * * *$ & $0.116^{* * *}$ & $0.082 * *$ & $0.120 * * *$ & 0.008 & 0.008 & 0.008 & -0.005 & $0.034^{* *}$ \\
\hline & $(0.009)$ & (0.009) & $(0.016)$ & $(0.016)$ & $(0.037)$ & $(0.034)$ & $(0.021)$ & $(0.008)$ & $(0.008)$ & (0.013) & $(0.014)$ & $(0.017)$ \\
\hline Observations & 86,876 & 86,876 & 44,029 & 44,029 & 9,783 & 12,169 & 22,077 & 42,847 & 42,847 & 18,977 & 15,756 & 8,114 \\
\hline R-squared & 0.004 & 0.004 & 0.003 & 0.003 & 0.009 & 0.007 & 0.002 & 0.008 & 0.008 & 0.006 & 0.010 & 0.018 \\
\hline
\end{tabular}

Table 5 reports heterogenous treatment effects on take-up, by baseline health spending risk. Risk is measured using the CDPS prospective risk score, based on diagnoses from 2015 hospitalizations and emergency room encounters. Column headers note sample specifications. All regressions control for ACA age-based community-rating premium ratio and region. Appendix Table 2 reports estimates from analogous specifications without controlling for the age-based premium ratios. Robust standard errors in parentheses. ${ }^{* * *} p<0.01,{ }^{* *} p<0.05,{ }^{*} p<0.1$ 
Table 6. Treatment Effect on the Average (Prospective) Risk of Enrolled Consumers

\begin{tabular}{|c|c|c|c|c|c|c|c|c|c|c|c|c|}
\hline \multicolumn{13}{|c|}{ Dependent Variable: In(Prospective Risk Score) } \\
\hline \multicolumn{13}{|c|}{ Panel A: Risk Unconditional on Age } \\
\hline \multirow{3}{*}{$\begin{array}{r}\text { Entry Path Sample } \\
\text { Income Sample } \\
\end{array}$} & \multirow{2}{*}{\multicolumn{2}{|c|}{$\begin{array}{r}\text { All } \\
\text { All }\end{array}$}} & \multicolumn{5}{|c|}{ Open Enrollment } & \multicolumn{5}{|c|}{ County Referral } \\
\hline & & & All & All & $\leq 180 \mathrm{FPL}$ & $180-250$ & $>250 \mathrm{FPL}$ & All & All & $\leq 180 \mathrm{FPL}$ & $180-250$ & $>250 \mathrm{FPL}$ \\
\hline & (1) & $(2)$ & (3) & (4) & (5) & (6) & (7) & (8) & (9) & $(10)$ & $(11)$ & $(12)$ \\
\hline Arm2345: All Letters & $\begin{array}{c}-0.051^{* * *} \\
(0.017)\end{array}$ & & $\begin{array}{c}-0.061^{* * *} \\
(0.019)\end{array}$ & & & & & $\begin{array}{l}-0.014 \\
(0.037)\end{array}$ & & & & \\
\hline Arm2: Reminder & & $\begin{array}{c}-0.044^{* *} \\
(0.021)\end{array}$ & & $\begin{array}{c}-0.055^{* *} \\
(0.023)\end{array}$ & $\begin{array}{c}-0.106 * * \\
(0.046)\end{array}$ & $\begin{array}{l}-0.025 \\
(0.040)\end{array}$ & $\begin{array}{l}-0.042 \\
(0.034)\end{array}$ & & $\begin{array}{c}0.000 \\
(0.048)\end{array}$ & $\begin{array}{c}0.042 \\
(0.070)\end{array}$ & $\begin{array}{c}0.004 \\
(0.075)\end{array}$ & $\begin{array}{l}-0.171 \\
(0.142)\end{array}$ \\
\hline Arm345: Subsidy Arms & & $\begin{array}{c}-0.053^{* * *} \\
(0.018)\end{array}$ & & $\begin{array}{c}-0.063 * * * \\
(0.020)\end{array}$ & $\begin{array}{c}-0.116^{* * *} \\
(0.040)\end{array}$ & $\begin{array}{l}-0.033 \\
(0.033)\end{array}$ & $\begin{array}{l}-0.049 \\
(0.030)\end{array}$ & & $\begin{array}{l}-0.018 \\
(0.038)\end{array}$ & $\begin{array}{l}-0.006 \\
(0.053)\end{array}$ & $\begin{array}{l}-0.016 \\
(0.059)\end{array}$ & $\begin{array}{l}-0.086 \\
(0.132)\end{array}$ \\
\hline Age-based Rating & $\mathrm{N}$ & $\mathrm{N}$ & $\mathrm{N}$ & $\mathrm{N}$ & $\mathrm{N}$ & $\mathrm{N}$ & $\mathrm{N}$ & $\mathrm{N}$ & $\mathrm{N}$ & $\mathrm{N}$ & $\mathrm{N}$ & $\mathrm{N}$ \\
\hline Observations & 7,945 & 7,945 & 6,201 & 6,201 & 1,810 & 1,933 & 2,458 & 1,744 & 1,744 & 851 & 655 & 238 \\
\hline R-squared & 0.002 & 0.002 & 0.002 & 0.002 & 0.008 & 0.001 & 0.002 & 0.000 & 0.000 & 0.001 & 0.000 & 0.009 \\
\hline \multicolumn{13}{|c|}{ Panel B: Risk, Conditional on Age Rating and Region } \\
\hline \multirow{3}{*}{$\begin{array}{r}\text { Funnel Sample } \\
\text { Income Sample } \\
\end{array}$} & $\mathrm{A}$ & All & \multicolumn{5}{|c|}{ Open Enrollment } & \multicolumn{5}{|c|}{ County Referral } \\
\hline & & All & All & All & $\leq 180 \mathrm{FPL}$ & $180-250$ & $>250 \mathrm{FPL}$ & All & All & $\leq 180 \mathrm{FPL}$ & $180-250$ & $>250 \mathrm{FPL}$ \\
\hline & $(1)$ & $(2)$ & (3) & (4) & (5) & (6) & (7) & $(8)$ & (9) & $(10)$ & $(11)$ & $(12)$ \\
\hline Arm2345: All Letters & $\begin{array}{c}-0.043^{* *} \\
(0.017)\end{array}$ & & $\begin{array}{c}-0.056 * * * \\
(0.019)\end{array}$ & & & & & $\begin{array}{l}-0.002 \\
(0.037)\end{array}$ & & & & \\
\hline Arm2: Reminder & & $\begin{array}{c}-0.037^{*} \\
(0.020)\end{array}$ & & $\begin{array}{c}-0.050 * * \\
(0.022)\end{array}$ & $\begin{array}{c}-0.086^{*} \\
(0.045)\end{array}$ & $\begin{array}{l}-0.017 \\
(0.039)\end{array}$ & $\begin{array}{l}-0.041 \\
(0.033)\end{array}$ & & $\begin{array}{c}0.007 \\
(0.048)\end{array}$ & $\begin{array}{c}0.089 \\
(0.067)\end{array}$ & $\begin{array}{l}-0.014 \\
(0.072)\end{array}$ & $\begin{array}{c}-0.257^{* *} \\
(0.120)\end{array}$ \\
\hline Arm345: Subsidy Arms & & $\begin{array}{c}-0.045^{* *} \\
(0.017)\end{array}$ & & $\begin{array}{c}-0.057^{* * *} \\
(0.019)\end{array}$ & $\begin{array}{c}-0.101^{* *} \\
(0.039)\end{array}$ & $\begin{array}{c}-0.019 \\
(0.032)\end{array}$ & $\begin{array}{l}-0.049 \\
(0.030)\end{array}$ & & $\begin{array}{l}-0.004 \\
(0.038)\end{array}$ & $\begin{array}{c}0.045 \\
(0.052)\end{array}$ & $\begin{array}{l}-0.029 \\
(0.057)\end{array}$ & $\begin{array}{l}-0.126 \\
(0.109)\end{array}$ \\
\hline ACA Age Rating Factor & $\begin{array}{l}0.201 * * * \\
(0.011)\end{array}$ & $\begin{array}{c}0.201 * * * \\
(0.011)\end{array}$ & $\begin{array}{l}0.185^{* * *} \\
(0.012)\end{array}$ & $\begin{array}{c}0.185^{* * *} \\
(0.012)\end{array}$ & $\begin{array}{c}0.217^{* * * *} \\
(0.022)\end{array}$ & $\begin{array}{c}0.227 * * * \\
(0.022)\end{array}$ & $\begin{array}{c}0.149 * * * \\
(0.018)\end{array}$ & $\begin{array}{c}0.259 * * * \\
(0.028)\end{array}$ & $\begin{array}{c}0.259 * * * \\
(0.028)\end{array}$ & $\begin{array}{c}0.252 * * * \\
(0.042)\end{array}$ & $\begin{array}{c}0.264 * * * \\
(0.044)\end{array}$ & $\begin{array}{c}0.284 * * * \\
(0.059)\end{array}$ \\
\hline Age-based Rating & $\mathrm{N}$ & $\mathrm{N}$ & $\mathrm{N}$ & $\mathrm{N}$ & $\mathrm{N}$ & $\mathrm{N}$ & $\mathrm{N}$ & $\mathrm{N}$ & $\mathrm{N}$ & $\mathrm{N}$ & $\mathrm{N}$ & $\mathrm{N}$ \\
\hline Observations & 7,945 & 7,945 & 6,201 & 6,201 & 1,810 & 1,933 & 2,458 & 1,744 & 1,744 & 851 & 655 & 238 \\
\hline R-squared & 0.065 & 0.065 & 0.059 & 0.059 & 0.086 & 0.085 & 0.052 & 0.091 & 0.091 & 0.109 & 0.114 & 0.187 \\
\hline
\end{tabular}

Table 6 reports treatment effects on average risk of enrolled individuals. The dependent variable is the CDPS prospective risk score, based on 2015 diagnoses from hospital and emergency room encounters. Panel A controls for Covered California's age-based community-rating premium ratio and region. Panel B reports controls for region, only. Robust standard errors in parentheses. ${ }^{* * *} p<0.01,{ }^{* *} p<0.05,{ }^{*} p<0.1$ 
Table 7. Treatment Effect on the Average (Concurrent) Risk of Enrolled Consumers

\begin{tabular}{|c|c|c|c|c|c|c|c|c|c|c|c|c|}
\hline \multicolumn{13}{|c|}{ Dependent Variable: In(Concurrent Risk Score) } \\
\hline \multicolumn{13}{|c|}{ Panel A: Risk Unconditional on Age } \\
\hline \multirow{3}{*}{$\begin{array}{r}\text { Entry Path Sample } \\
\text { Income Sample } \\
\end{array}$} & \multicolumn{2}{|c|}{ All } & \multicolumn{5}{|c|}{ Open Enrollment } & \multicolumn{5}{|c|}{ County Referral } \\
\hline & \multicolumn{2}{|c|}{ All } & All & All & $\leq 180 \mathrm{FPL}$ & $180-250$ & $>250 \mathrm{FPL}$ & All & All & $\leq 180 \mathrm{FPL}$ & $180-250$ & $>250 \mathrm{FPL}$ \\
\hline & $(1)$ & $(2)$ & (3) & (4) & $(5)$ & (6) & $(7)$ & (8) & (9) & $(10)$ & $(11)$ & $(12)$ \\
\hline \multirow[t]{2}{*}{ Arm2345: All Letters } & $-0.063^{*}$ & & $-0.106 * *$ & & & & & 0.073 & & & & \\
\hline & $(0.036)$ & & $(0.042)$ & & & & & $(0.073)$ & & & & \\
\hline \multirow[t]{2}{*}{ Arm2: Reminder } & & -0.035 & & -0.072 & -0.164 & -0.025 & -0.058 & & 0.086 & 0.086 & 0.068 & 0.055 \\
\hline & & $(0.045)$ & & $(0.052)$ & $(0.101)$ & $(0.094)$ & $(0.078)$ & & $(0.089)$ & $(0.132)$ & $(0.151)$ & $(0.209)$ \\
\hline \multirow[t]{2}{*}{ Arm345: Subsidy Arms } & & $-0.072 *$ & & $-0.118 * * *$ & $-0.248 * * *$ & $-0.158 * *$ & -0.013 & & 0.069 & 0.149 & 0.012 & -0.068 \\
\hline & & $(0.037)$ & & $(0.043)$ & $(0.084)$ & $(0.078)$ & $(0.065)$ & & $(0.075)$ & $(0.107)$ & $(0.135)$ & $(0.174)$ \\
\hline Controls & $\mathrm{N}$ & $\mathrm{N}$ & $\mathrm{N}$ & $\mathrm{N}$ & $\mathrm{N}$ & $\mathrm{N}$ & $\mathrm{N}$ & $\mathrm{N}$ & $\mathrm{N}$ & $\mathrm{N}$ & $\mathrm{N}$ & $\mathrm{N}$ \\
\hline Observations & 11,472 & 11,472 & 8,685 & 8,685 & 2,445 & 2,565 & 3,655 & 2,787 & 2,787 & 1,264 & 969 & 548 \\
\hline R-squared & 0.000 & 0.000 & 0.001 & 0.001 & 0.004 & 0.002 & 0.000 & 0.000 & 0.000 & 0.002 & 0.000 & 0.001 \\
\hline \multicolumn{13}{|c|}{ Panel B: Risk, Conditional on Age Rating and Region } \\
\hline \multirow{3}{*}{$\begin{array}{r}\text { Entry Path Sample } \\
\text { Income Sample }\end{array}$} & A & III & \multicolumn{5}{|c|}{ Open Enrollment } & \multicolumn{5}{|c|}{ County Referral } \\
\hline & \multicolumn{2}{|c|}{ All } & All & All & $\leq 180 \mathrm{FPL}$ & $180-250$ & $>250 \mathrm{FPL}$ & All & All & $\leq 180 \mathrm{FPL}$ & $180-250$ & $>250 \mathrm{FPL}$ \\
\hline & $(1)$ & $(2)$ & $(3)$ & (4) & $(5)$ & $(6)$ & $(7)$ & $(8)$ & (9) & $(10)$ & $(11)$ & $(12)$ \\
\hline \multirow[t]{2}{*}{ Arm2345: All Letters } & -0.023 & & $-0.067^{*}$ & & & & & 0.105 & & & & \\
\hline & $(0.034)$ & & $(0.039)$ & & & & & $(0.071)$ & & & & \\
\hline \multirow[t]{2}{*}{ Arm2: Reminder } & & 0.008 & & -0.030 & -0.085 & -0.021 & -0.011 & & 0.110 & 0.164 & 0.059 & -0.047 \\
\hline & & $(0.043)$ & & $(0.049)$ & $(0.097)$ & $(0.090)$ & $(0.074)$ & & $(0.087)$ & $(0.132)$ & $(0.150)$ & $(0.206)$ \\
\hline \multirow[t]{2}{*}{ Arm345: Subsidy Arms } & & -0.034 & & $-0.080 * *$ & $-0.189 * *$ & -0.122 & 0.008 & & 0.104 & $0.272 * * *$ & 0.023 & -0.242 \\
\hline & & $(0.035)$ & & $(0.041)$ & $(0.080)$ & $(0.075)$ & $(0.061)$ & & $(0.073)$ & $(0.104)$ & $(0.135)$ & $(0.179)$ \\
\hline \multirow[t]{2}{*}{ ACA Age Rating Factor } & $7.584^{* * *}$ & $7.585^{* * *}$ & $7.721 * * *$ & $7.723 * * *$ & $7.954 * * *$ & $7.629 * * *$ & $7.630 * * *$ & $7.087^{* * *}$ & $7.087^{* * *}$ & $6.858 * * *$ & $6.694 * * *$ & $8.220 * * *$ \\
\hline & $(0.202)$ & $(0.202)$ & $(0.232)$ & $(0.232)$ & $(0.465)$ & $(0.455)$ & $(0.334)$ & $(0.417)$ & $(0.417)$ & $(0.616)$ & $(0.709)$ & $(0.954)$ \\
\hline Controls & $\mathrm{N}$ & $\mathrm{N}$ & $\mathrm{N}$ & $\mathrm{N}$ & $\mathrm{N}$ & $\mathrm{N}$ & $\mathrm{N}$ & $\mathrm{N}$ & $\mathrm{N}$ & $\mathrm{N}$ & $\mathrm{N}$ & $\mathrm{N}$ \\
\hline Observations & 11,472 & 11,472 & 8,685 & 8,685 & 2,445 & 2,565 & 3,655 & 2,787 & 2,787 & 1,264 & 969 & 548 \\
\hline R-squared & 0.111 & 0.111 & 0.115 & 0.115 & 0.128 & 0.111 & 0.120 & 0.104 & 0.104 & 0.107 & 0.111 & 0.168 \\
\hline
\end{tabular}

$\overline{\text { Table } 7 \text { reports treatment effects on average risk of enrolled individuals. The dependent variable is a concurrent risk score, based on realized } 2016 \text { claims }}$ data. Column headers note sample specifications. Panel A controls for Covered California's age-based community-rating premium ratio and region. Panel $B$ reports controls for region, only. Robust standard errors in parentheses. ${ }^{* * *} p<0.01,{ }^{* *} p<0.05,{ }^{*} p<0.1$ 
Table 8. Indirect Utility Model Logit Regressions and $\triangle$ WTP Estimates

\begin{tabular}{|c|c|c|c|c|c|c|c|c|c|c|}
\hline \multirow{3}{*}{$\begin{array}{r}\text { Entry Sample } \\
\text { Income Sample } \\
\end{array}$} & \multirow{2}{*}{\multicolumn{2}{|c|}{$\begin{array}{l}\text { All } \\
\text { All }\end{array}$}} & \multicolumn{4}{|c|}{ Open Enrollment } & \multicolumn{4}{|c|}{ County Referral } \\
\hline & & & \multicolumn{2}{|c|}{ All } & \multicolumn{2}{|c|}{$\mathrm{Y}<180 \mathrm{FPL}$} & \multicolumn{2}{|c|}{ All } & \multicolumn{2}{|c|}{$\mathrm{Y}<180 \mathrm{FPL}$} \\
\hline & $(1)$ & $(2)$ & (3) & $(4)$ & $(5)$ & $(6)$ & $(7)$ & $(8)$ & (9) & $(10)$ \\
\hline$\alpha$ & $\begin{array}{c}0.276^{* * *} \\
(0.015)\end{array}$ & $\begin{array}{c}0.276^{* * *} \\
(0.013)\end{array}$ & $\begin{array}{c}0.265^{* * *} \\
(0.017)\end{array}$ & $\begin{array}{c}0.265^{* * *} \\
(0.014)\end{array}$ & $\begin{array}{c}0.353^{* * *} \\
(0.034)\end{array}$ & $\begin{array}{c}0.347^{* * *} \\
(0.028)\end{array}$ & $\begin{array}{c}0.487^{* * *} \\
(0.047)\end{array}$ & $\begin{array}{c}0.480^{* * *} \\
(0.044)\end{array}$ & $\begin{array}{c}0.762^{* * *} \\
(0.087)\end{array}$ & $\begin{array}{c}0.740^{* * *} \\
(0.084)\end{array}$ \\
\hline$\tilde{\alpha}$ & $\begin{array}{c}0.001 \\
(0.013)\end{array}$ & & $\begin{array}{c}0.001 \\
(0.016)\end{array}$ & & $\begin{array}{l}-0.010 \\
(0.029)\end{array}$ & & $\begin{array}{l}-0.011 \\
(0.024)\end{array}$ & & $\begin{array}{l}-0.036 \\
(0.035)\end{array}$ & \\
\hline$\gamma_{\text {Remind }}$ & $\begin{array}{c}0.142 * * * \\
(0.039)\end{array}$ & $\begin{array}{l}0.142 * * * \\
(0.039)\end{array}$ & $\begin{array}{c}0.154 * * * \\
(0.045)\end{array}$ & $\begin{array}{l}0.154^{* * *} \\
(0.045)\end{array}$ & $\begin{array}{c}0.172 * * \\
(0.087)\end{array}$ & $\begin{array}{l}0.172^{* *} \\
(0.087)\end{array}$ & $\begin{array}{c}0.100 \\
(0.081)\end{array}$ & $\begin{array}{c}0.101 \\
(0.081)\end{array}$ & $\begin{array}{l}-0.056 \\
(0.116)\end{array}$ & $\begin{array}{l}-0.055 \\
(0.116)\end{array}$ \\
\hline$\gamma_{\text {Inform }}$ & $\begin{array}{l}0.007 \\
(0.031)\end{array}$ & $\begin{array}{c}0.007 \\
(0.031)\end{array}$ & $\begin{array}{l}-0.015 \\
(0.035)\end{array}$ & $\begin{array}{l}-0.015 \\
(0.035)\end{array}$ & $\begin{array}{c}0.069 \\
(0.073)\end{array}$ & $\begin{array}{c}0.060 \\
(0.068)\end{array}$ & $\begin{array}{c}0.089 \\
(0.070)\end{array}$ & $\begin{array}{l}0.076 \\
(0.064)\end{array}$ & $\begin{array}{l}0.210^{*} \\
(0.111)\end{array}$ & $\begin{array}{l}0.152 \\
(0.094)\end{array}$ \\
\hline Constant & $\begin{array}{c}-0.925^{* * *} \\
(0.116)\end{array}$ & $\begin{array}{c}-0.925^{* * *} \\
(0.116)\end{array}$ & $\begin{array}{c}-1.018^{* * *} \\
(0.137)\end{array}$ & $\begin{array}{c}-1.018 * * * \\
(0.137)\end{array}$ & $\begin{array}{l}-0.294 \\
(0.746)\end{array}$ & $\begin{array}{l}-0.292 \\
(0.746)\end{array}$ & $\begin{array}{c}-1.920 * * * \\
(0.257)\end{array}$ & $\begin{array}{c}-1.913^{* * *} \\
(0.257)\end{array}$ & $\begin{array}{l}-0.891 \\
(0.936)\end{array}$ & $\begin{array}{l}-0.844 \\
(0.935)\end{array}$ \\
\hline Controls & $\mathrm{Y}$ & $\mathrm{Y}$ & $\mathrm{Y}$ & $Y$ & $Y$ & $Y$ & $\mathrm{Y}$ & $\mathrm{Y}$ & $\mathrm{Y}$ & $\mathrm{Y}$ \\
\hline Observations & 87,394 & 87,394 & 44,248 & 44,248 & 9,833 & 9,833 & 42,800 & 42,800 & 19,117 & 19,117 \\
\hline$\Delta W T P($ Reminder $)$ & - & $51.37 * * *$ & - & $58.20 * * *$ & - & $49.48^{* *}$ & - & 20.98 & - & -7.449 \\
\hline \multirow{3}{*}{$\Delta W T P($ Subsidy Info $)$} & - & 14.37 & - & 17.22 & - & 25.41 & - & 16.89 & - & 15.71 \\
\hline & - & 2.691 & - & -5.593 & - & 17.32 & - & 15.90 & - & 20.49 \\
\hline & - & 11.20 & - & 13.36 & - & 19.64 & - & 13.39 & - & 12.95 \\
\hline \multicolumn{11}{|l|}{ Calibration using FHS (2019) } \\
\hline $\begin{array}{c}\beta_{\text {Reminder }} \\
\Delta W T P(\text { Reminder })\end{array}$ & \multicolumn{2}{|c|}{0.153} & & & & & & & & \\
\hline $\begin{array}{c}\beta_{\text {SubsidyLetters }} \\
\Delta W T P(\text { Subsidy Info })\end{array}$ & \multicolumn{2}{|c|}{$\begin{array}{c}0.002 \\
0.39\end{array}$} & & & & & & & & \\
\hline
\end{tabular}

Table 8 reports estimates from the indirect utility model (equation 4). $\alpha$ represents the effect of the subsidy on indirect utility. $\tilde{\alpha}$ represents how the effectof the subsidy on indirect utility is impacted by receiving a subsidy-reporting letter. $\gamma_{\text {Inform }}$ represents the direct effect of the subsidy-reporting letters on indirect utility. $\gamma_{\text {Remind }}$ represents the direct effect of receiving reminder information on indirect utility. $\triangle W T P$ reports the implied change in measured WTP for marketplace coverage due to receipt of the letters, as specified in equations (5) and (6). As noted in the text, we assume $\tilde{\alpha}=0$ in calculating $\triangle W T P . * * * p<0.01, * * p<0.05, * p<0.1$ 